\title{
WestVirginiaUniversity
}

THE RESEARCH REPOSITORY @ WVU

Graduate Theses, Dissertations, and Problem Reports

2016

\section{Voluntary Wheel Running Improves Recovery from Muscle Disuse in Mice}

Matthew J. Brooks

Follow this and additional works at: https://researchrepository.wvu.edu/etd

\section{Recommended Citation}

Brooks, Matthew J., "Voluntary Wheel Running Improves Recovery from Muscle Disuse in Mice" (2016). Graduate Theses, Dissertations, and Problem Reports. 5263.

https://researchrepository.wvu.edu/etd/5263

This Thesis is protected by copyright and/or related rights. It has been brought to you by the The Research Repository @ WVU with permission from the rights-holder(s). You are free to use this Thesis in any way that is permitted by the copyright and related rights legislation that applies to your use. For other uses you must obtain permission from the rights-holder(s) directly, unless additional rights are indicated by a Creative Commons license in the record and/ or on the work itself. This Thesis has been accepted for inclusion in WVU Graduate Theses, Dissertations, and Problem Reports collection by an authorized administrator of The Research Repository @ WVU. For more information, please contact researchrepository@mail.wvu.edu. 


\title{
Voluntary wheel running improves recovery from muscle disuse in mice
}

\author{
Matthew J. Brooks, B.S. \\ Thesis submitted \\ to the School of Medicine, Division of Exercise Physiology \\ at West Virginia University \\ in partial fulfillment of the requirements for the degree of \\ Master of Science in \\ Exercise Physiology
}

Stephen E. Alway, Ph.D., Chair

Randall W. Bryner, Ed.D

Janet C. Tou, Ph.D.

Junaith S. Mohamed, Ph.D.

Division of Exercise Physiology

Morgantown, WV

2016

Key Words: hindlimb suspension, satellite cells, voluntary wheel running, atrophy 


\title{
ABSTRACT \\ Voluntary wheel running improves recovery from muscle disuse in mice
}

\author{
Matthew J. Brooks
}

The reloading of atrophied muscles from weightlessness or disuse results in injury and prolonged recovery. Satellite cells, or muscle stem cells, have a key role in facilitating injuryinduced muscle repair but have not been shown to be required in muscle remodeling following atrophy. However, it has been less clear if low-impact exercise, such as voluntary wheel running, could provide a sufficient stimulus to enhance muscle recovery from atrophy through satellite cell activation. This study aimed to determine if voluntary wheel running improved recovery from muscle disuse following hindlimb suspension unloading (HSU), and if the recovery was associated with exercise-induced satellite cell activity. Young adult male and female C57BL/6 background mice ( $\mathrm{n}=6$ /group) were subjected to either 14 days of normal weight bearing, 14 days of HSU, 14 days of HSU + 14 days of re-ambulation, 14 days of voluntary wheel running, or 14 days of HSU +14 days of voluntary wheel running. Mice were given 5-bromo-2'-deoxyuridine (BrdU) in their drinking water during the final 14 days of the experiment to measure satellite cell proliferation in gastrocnemius muscle fibers. HSU significantly reduced in vivo maximal force and decreased the rate of fatigue in the plantarflexor muscles. Voluntary wheel running during reloading after HSU significantly improved resistance to fatigue, which was associated with significant increases in both muscle fiber cross sectional area (CSA) and an increased percentage of oxidative type IIA muscle fibers in the gastrocnemius muscle as compared to the mice recovering without exercise. BrdU positive nuclei that had proliferated and were located inside the muscle sarcolemma were identified by immunohistochemical labeling and quantified in tissue cross sections. Following HSU, wheel running mice had a significantly greater percentage of BrdU positive nuclei that were inside gastrocnemius muscle fibers. Western blot analysis showed HSU mice with wheel running had a higher MyoD to Pax7 ratio as compared to mice that did not exercise after HSU. Mice in the wheel running group had significantly improved fatigue resistance, a significantly increased oxidative fiber phenotype, and significantly increased fiber CSA as compared to non-exercised animals after HSU. These results indicate that voluntary wheel running increased satellite cell activity during the recovery phase following HSU and this was associated with improved recovery from muscle disuse. While satellite cells did not exhibit increased activity in passive recovery (non-wheel running), manipulating their activation through low-impact exercise appeared to enhance morphological recovery and improve muscle function. 


\section{Table of Contents}

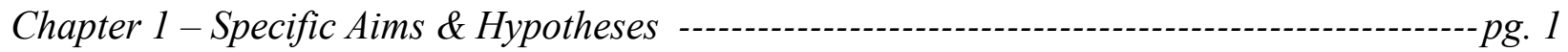

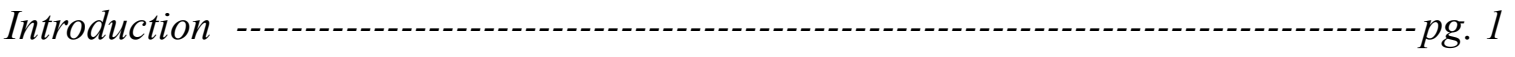

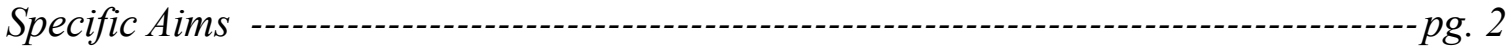

Specific Aim \#1

Hypothesis \#1

Specific Aim \#2

Hypothesis \#2

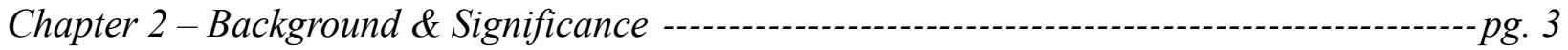

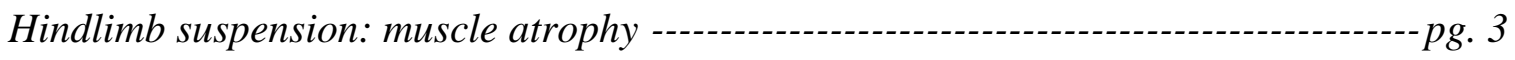

Hindlimb suspension: reloading and exercise --- 6

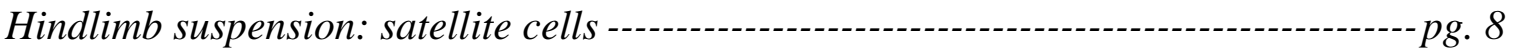

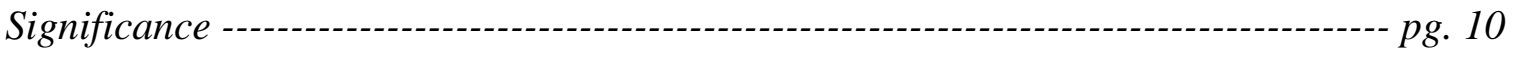

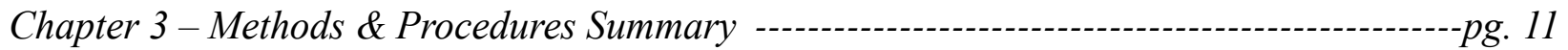

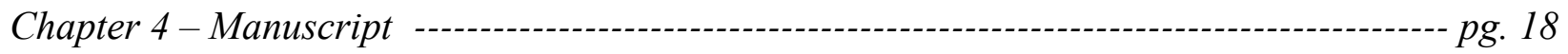

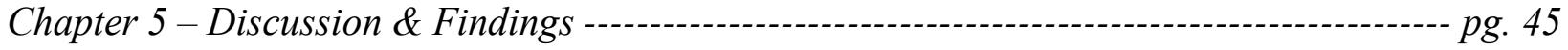

Chapter 6-Limitations --1.-- 48

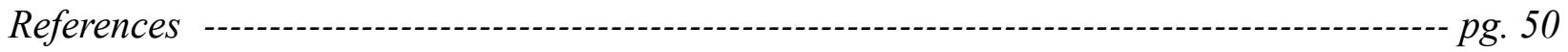

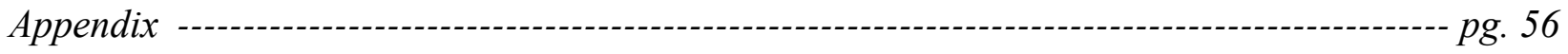




\section{Chapter 1 -Specific Aims \& Hypotheses}

\section{Introduction}

A high degree of muscle plasticity is evident in models of skeletal muscle atrophy and recovery. Muscle atrophy, whether occurring from a primary cause such as unloading (i.e. microgravity, bed rest, or inactivity) or secondarily to changes in age, nutrition, or disease, results in an inherent loss of muscle function and strength that contributes to mobility impairment and decreased quality of life. Understanding and designing effective strategies and therapies to address the reloading phase following muscle wasting has critical implications for reducing healthcare costs, improving rehabilitation, and preventing further damage.

Satellite cells are quiescent muscle stem that can be activated following muscle injury or an increase in mechanical load [1]. However, the role of satellite cells in recovery from muscle from atrophy during the reloading period is unclear. It is not currently known if exercise-induced satellite cell activation can improve muscle rehabilitation. Our preliminary data in mice suggest that satellite cells are not inherently activated by simple re-ambulation following atrophy, but we found that introducing low-impact exercise during recovery induces satellite cell activation, which might alter the mechanism and/or magnitude of recovery. Specifically, our preliminary data in C57BL/6 mice suggest that voluntary wheel running increases 5-bromo-2'-deoxyuridine (BrdU) incorporation into the gastrocnemius muscle following hindlimb-suspension unloading (HSU). Additionally, the voluntary exercise appeared to result in improved fiber cross sectional area (CSA) and improved fatigue resistance.

The primary objective of this study was to determine whether rehabilitative voluntary wheel running can improve the functional recovery of muscle and enhance satellite cell 
involvement following HSU in a mouse model. The central hypothesis was that voluntary wheelrunning during reloading following hindlimb unloading-induced atrophy would provide a sufficient stimulus to enhance skeletal muscle functional and morphological recovery that would activate satellite cells. Our rationale for conducting this study was to further investigate claims that voluntary wheel running improves atrophy recovery [2] and determine novel roles for satellite cells in improving muscle recovery following disuse-induced atrophy.

Specific Aim 1: Determine the effect of voluntary wheel running on the recovery of muscle function following HSU. The working hypothesis was that voluntary wheel running after HSU, as a mild exercise, will improve fatigue resistance while not having an effect on maximal force.

Specific Aim 2: Determine the effect of voluntary wheel running on satellite cell proliferation and muscle morphology following HSU. The working hypothesis was that voluntary wheel running will increase satellite cell proliferation, which will result in improved muscle fiber CSA and an increased ratio of type I muscle fibers to type ii muscle fibers. 


\section{Chapter 2-Background \& Significance}

\section{Hindlimb suspension: muscle atrophy}

The unweighted environment of outer space reduces muscle load, induces atrophy, and reduces muscle performance in humans [3-6]. Similar effects were seen in rodents on the Cosmos biosatellite program [7] and this led to the development of HSU model for rodents in order to provide a ground-based simulation to study muscle atrophy in humans [8]. To validate this model, the Cosmos 2044 spaceflight experiment used HSU as a control group for direct comparison to rats in microgravity [9]. It was found that HSU and spaceflight were comparable in their ability to induce changes in rat muscle morphology, including fiber type switching from slow-to-fast fibers, and a decrease in the mass of the soleus [9]. Fast-twitch muscles exhibited a lesser response to both microgravity and HSU, with no changes in fiber size. Only the ratio of intermediate fibers to total fiber composition was reduced in both conditions [10-12]. Post-flight, the repair of soleus and gastrocnemius muscles were similar in both the HSU and spaceflight rats [13].

HSU atrophy preferentially affects slow-twitch muscles, such as the soleus [14]. Soleus atrophy results in detrimental effects including decreased peak force [6], increased maximal shortening velocity [3,15], increased rate of fatigue in the soleus [16], decreased CSA [17], and a shift from slow-to-fast twitch muscle fibers [2]. Studies in both human and rat models have found that the soleus, a postural muscle, atrophies more than the gastrocnemius [32]. While most studies in rats have consistently found that slow-twitch fibers are selectively atrophied in the soleus, human studies did not always exhibit this preferential atrophy in a similar exclusiveness [14]. Although originally designed for rats, the HSU model was also adapted for mice [18]. The mouse soleus is composed of mixed fiber types (composition dependent on mouse strain), unlike in rats, which have predominantly slow-twitch soleus muscle (>85\% type I fibers) [19]. In mice, the 
atrophic changes to the soleus were characterized by a $33-39 \%$ reduction of fiber size in type I fibers, a $21-25 \%$ reduction in type IIa fibers, and a $16 \%$ reduction in type IIx/b fibers [17]. Moreover, unlike the soleus muscle in rats, the mouse soleus does not appear to decrease myosin heavy chain (MHC) I or MHC IIa expression, or increase MHC IIx/b expression following HSU [20]. It is hypothesized that the apparent selective atrophy in rat soleus muscles is a result of greater composition of slow-twitch fibers, causing a greater specific effect when changes are made to motor unit recruitment demands [17]. While the mouse model did not see the same degree of selective fiber atrophy or reduction in MHC I expression, overall the soleus muscle had a oxidative-to-glycolytic shift in fiber composition.

Muscle atrophy occurs via increased protein degradation and/or decreased protein synthesis [21]. The mechanism of disuse-induced atrophy remains to be elucidated and is the subject of debate. It was initially believed that oxidative stress was an important regulator of disuse atrophy, and may still be an effective target in therapy [22]. As a prophylactic therapy, preconditioning the muscle to higher levels of oxidative stress through endurance exercise prior to HSU attenuated the HSU-induced loss of fatigue resistance in the soleus, the myofibrillar protein concentration loss, the oxidative-to-glycolytic fiber type switching, and the loss of heat shock protein (HSP)72 [23]. However, preconditioning was unable to preserve muscle mass and maximal tetanic tension during HSU. It was then hypothesized that the preservation of HSPs was partially responsible for these benefits through reduction of oxidative stress [23]. Future research is necessary to understand how the preconditioning exercise protected the muscle. However, other recent research has suggested that disuse-induced atrophy is driven by other factors than oxidative stress [24-26]. While oxidative stress does occur during HSU, it has been shown that the endogenous antioxidant defense system is able to efficiently respond to the increases in reactive 
oxygen species, protecting a homeostatic redox environment during at least the first 14 days of HSU [26,27].

An investigation of the early responses of the muscle occurring during unloading has indicated that atrophy occurs as early as 3 days into HSU and is accompanied by decreases in mitochondrial fusion, which in turn causes mitochondrial dysfunction [28]. The resultant decrease in adenosine triphosphate (ATP) production activated AMP-activated protein kinase (AMPK) [28], which is known to have a role in upregulating both the ubiquitin-proteasome system and autophagy pathway, results in increased protein degradation and inhibited muscle hypertrophy [29]. To explore the extent of AMPK's role in protein regulation in the slow-twitch soleus muscle of mice, a dominant-negative mouse model was used to reduce skeletal muscle AMPK activity during HSU [30]. The results showed that reduction of AMPK has a protective role in partially attenuating muscle atrophy through modulation of the ubiquitin-proteasome and autophagy pathways. While it is apparent that AMPK regulates some of the components of muscle atrophy that affect protein degradation, it remains to be determined whether it has a significant effect on physiological parameters of muscle function.

While the mechanism of disuse-induced atrophy is not well understood, the effects are clear. Disuse-induced atrophy causes changes in muscle fiber type composition, losses of muscle mass and maximal force, and increases the muscle fatigue rate in the soleus. Understanding the effects of reloading skeletal muscle is necessary for designing appropriate rehabilitation without further damaging the muscle. 


\section{Hindlimb suspension: reloading and exercise}

Skeletal muscle is highly plastic and the changes caused by HSU are reversible. However, reloading the hindlimb muscles following HSU can have adverse effects. Mice are able to recover soleus muscle mass and force after 15 days of reloading, but their resistance to fatigue continues to worsen over this period [20]. These results in mice are similar to data that have been reported in rats, however, rats also failed to fully recover muscle force production after 14 days of reloading [31]. Similarly, post-spaceflight human data shows that muscle strength further decreases during the reloading period [32] independent of muscle volume recovery [33]. The recovery of muscle mass, fiber width, and the near full recovery of CSA [34] were unable to fully restore muscle functionality [20,31]. This discrepancy is due to reloading-induced muscle damage. Early studies found evidence of lesions in muscle sarcomeres. It is suggested that this is caused by fiber length shortening during HSU [31,35-38]. Upon reloading, the muscle is then stretched and susceptible to injury that is similar to eccentric exercise muscle damage $[31,39,40]$.

As there is no current method to prevent the atrophy of muscle during unloading and because reloading itself may cause more damage, researchers are currently working to understand the effects of exercise therapy on the muscle during reloading. In a broad perspective, muscle unloading and exercise training are inversely related [41]. This relationship makes various forms and durations of exercise reasonable targets for reversing the atrophic effects of HSU and restoring muscle function. Following HSU, one study found that 7 days of voluntary wheel running in mice appears to shorten the recovery time of muscle mass and CSA [2]. However, this study failed to have a suitable control group to compare the recovery from HSU without exercise, causing the authors to rely on data from other studies. During the first 4 days of the reloading period mice ran less distance at a slower velocity than non-suspended mice with access to wheel running, but it is 
unclear if this difference was a result of the weakened muscles from HSU-induced atrophy, reloading-induced damage, or both [2]. Compared to results from studies with similar reloading periods without exercise, voluntary exercise enhanced recovery of muscle fiber CSA and improved the ability of mice to regain muscle weight $[2,31,42]$, but failed to recover maximal tetanic force. Without a control group, it cannot be determined whether exercise improved the rate of muscle recovery. Overall, the study found that ad libitum, low intensity exercise improved certain aspects of muscle recovery even though contractile strength did not recover after 7 days [2].

Research in rats has found that endurance exercise training also improves recovery, but can also damage the muscle [43]. One study used a rigorous treadmill raining protocol (60 min/day at $28 \mathrm{~m} / \mathrm{min}$ on a $15 \%$ grade by $3^{\text {rd }}$ week) in rats during reloading [43]. Compared to the control recovery group, only the trained rats were observed to fully reverse the morphological changes of muscle atrophy and to maintain a restored CSA and mass of the soleus by 28 days of recovery. During this recovery process, however, it was observed that rats with training had more pronounced clusters of damaged (injured) fibers, smaller fiber CSA, and an increase in type IIc fibers that peaked at approximately 14 days. These early phase indicators of worsened recovery were only transient and by 28 days of reloading, the type IIc fibers were absent and normal muscle morphology was restored [43]. In the trained rats, it remains unclear if the transient injury was necessary for the rats to have the fully recovery by 28 days. Unlike trained rats, the sedentary rats recovered body mass and CSA by 14 days, but were unable to maintain these gains. It remains to be determined if endurance training is better used after 14 days of sedentary recovery rather than immediately following HSU.

As previously stated, the muscular damage during the initial phase of HSU resembles the injury caused by unaccustomed eccentric exercise [39], including damaged myofibers and 
mononuclear cell infiltration [36,37,44-46]. While the mechanism is not well understood, a prophylactic therapy known as the 'repeated bout effect' has shown that conditioning bouts of eccentric exercise provides a protective effect against muscle damage if later subjected to an injury [47]. To explore if this protective effect translates to HSU recovery injury, rats underwent two weeks of eccentric resistance exercise followed by 7 days of HSU and were then examined after a 16-19 hour reloading period [47]. While the repeated bout effect did not attenuate muscle mass loss, there was a benefit of significantly decreasing the degree of myofibrillar damage [47]. These data are in contrast to previous notions that the degree of myofibrillar damage and the amount of atrophy are directly correlated [35]. Another noteworthy observation from this study was that the effects of pre-training persisted through 7 days of unloading, meaning that for at least short periods of unloading, prior treatment is protective [47]. The mechanism through which the repeated bout effect protects against eccentric damage in not well defined, but further investigation could provide insight into potential targets for preventing reloading induced injuries.

\section{Hindlimb suspension: satellite cells}

Satellite cells are quiescent muscle stem cells that lie between the basal lamina and sarcolemma of myofibers and are known to be vital for muscle growth and repair [48]. However, it is relatively unclear and understudied whether satellite cells are activated and utilized following muscle atrophy. Aged rats that were given green tea had greater satellite cell proliferation in the HSU reloading period $[49,50]$. While the studies were unable to directly attribute reloading improvement to satellite cells [50], it was hypothesized that satellite cells do play a role in restoring the muscle after HSU.

Once activated, satellite cells either proliferate (sustaining a pool of satellite cells), differentiate and form new muscle fibers, or donate their nuclei by fusing with existing myofibers 
$[1,51]$. The myonuclear domain theory states that within a muscle fiber, each nuclei is responsible for a certain theoretical amount of cytoplasm [52]. During atrophy, myonuclei are lost, while in hypertrophy the total number of myonuclei increase. The hypertrophic nuclei increase is likely a result of satellite cell fusion [52]. The validity of the myonuclear domain theory is contested because while nuclei and cytoplasm are reduced in HSU, it is unclear whether they maintain the same ratio [53]. Regardless, satellite cells and their role in hypertrophy during reloading is a mechanism of substantial interest and debate. In one HSU study, $\gamma$-irradiation was used to inhibit satellite cell proliferation in mice [54]. The study found that muscle growth occurred normally for the first week after reloading, but was inhibited during the second week. The failure to restore muscle mass indicates that satellite cells are critical in the restoration of atrophied muscle. Furthermore, the authors hypothesized that increasing the proliferative capacity of satellite cells could enhance recovery [54]. This hypothesis was tested in aged rats using $\beta$-hydroxy- $\beta$ methylbutyrate (HMB) [55], a leucine metabolite that has been shown to increase proliferation of myoblasts in vitro [56]. The study found that HMB increased satellite cell proliferation, which correlated with improved recovery of plantaris muscle mass and CSA [55]. In contrast, a separate study used a tamoxifen-induced depletion of satellite cells in mice (aged 4-5 months) and found that recovery of muscle mass and force was unaffected [34]. These results suggest that satellite cells are not necessary during reloading following HSU, and rather the myonuclear domain size adapts to a new set point [34]. The reason for contrasting results with the study using $\gamma$-irradiation may be due to unintentional side effects of the $\gamma$-irradiation, an incomplete knockout of satellite cells, or the possibility that mice of different ages (9-11 weeks in the $\gamma$-irradiation study and 4-5 months in the tamoxifen study) have different satellite cell requirements [34,54]. If satellite cells 
are not inherently activated during reloading, providing a stimulus to activate satellite cells could benefit the recovery process.

Voluntary wheel running has been shown to increase satellite cell proliferation [57-59]. The one study using voluntary wheel running during recovery from HSU did not report any adverse injury during reloading, but it also did not investigate whether the exercise was sufficient to stimulate satellite cell activity [2]. With few studies investigating the mechanism of satellite cells in reloading following atrophy and the lack of consistent data, this study is necessary to better understand the role of satellite cells.

\section{Significance}

The current study was designed to specifically address two unanswered questions in hindlimb suspension research: (1) does voluntary exercise enhance the recovery process, and (2) will satellite cells be activated by voluntary wheel running during recovery? By utilizing in vivo force measurements, this study is novel in its ability to use repeated measures to monitor maximal force and fatigue measurements throughout the recovery. In vivo measurements are advantageous over the commonly used ex vivo measurements in that they are non-invasive and maintain the physiological environment of the muscle that would be disrupted through the surgical removal of the muscle and its isolation from its blood flow dependent energy and oxygen supply [20,60]. 


\title{
Chapter 3 -Methods and Procedures Summary
}

\author{
Study Design Overview
}

Our study was conducted using 5 mouse groups ( $\mathrm{n}=6$ /group). Three groups were subjected to 14 days of HSU to observe the effects of HSU without recovery (group: HSU), normal ambulation HSU recovery for 14 days (group: HSU+NoWR), and voluntary wheel running HSU recovery for 14 days (group: HSU+WR). 2 groups of non-suspended mice were used as controls. One was a cage control (group: Control) and the other was a cage control with voluntary wheel running control (group: ControlWR). As shown in Figure 1, in vivo maximal force and fatigue resistance were determined at day $0,14,21$, and 28 (as applicable) in the mice to map the effect of HSU (day 14), and voluntary wheel running during recovery (day 21 and 28). Mice were then sacrificed and tissues were subjected to experimental procedures to investigate morphological adaptations and satellite cell activity. The study design isolates the effects of voluntary wheel running in the HSU+WR group for direct comparison to reambulation recovery (HSU+NoWR) and non-HSU voluntary wheel running (ControlWR) to accurately evaluate previously described specific aims and hypotheses.

The mouse gastrocnemius muscle was studied for morphological comparison, as it comprises greater than $85 \%$ of the plantarflexion muscle mass (Brooks, unpublished data), making it the most relevant and functionally important plantarflexor muscle for recovery. The gastrocnemius is comprised of distinct areas of mixed fiber types or areas of solely type IIb/x fibers, with the areas of mixed fiber types being most effected by HSU and voluntary wheel running [20,57]. For analytical purposes, this study used published methods [61] to evaluate the 
areas of mixed fibers (Appendix Figure 2). For Western blots and 5-bromo-2'-deoxyuridine (BrdU) quantification, the entire gastrocnemius was analyzed.

\section{Mouse Model}

Young adult (4-5 months of age), male and female C57BL/6 mice were obtained from Jackson Labs and randomly assigned to five groups $(n=6)$ : 14 days of normal weight bearing (Control), 14 days of HSU (HSU), 14 days of HSU + 14 days of re-ambulation (HSU+NoWR), 14 days of voluntary wheel running (ControlWR), or 14 days of HSU +14 days of voluntary wheel running (HSU+WR). BrdU was provided in the drinking water $(0.8 \mathrm{mg} / \mathrm{ml})$ during the final 14 days of the experiment to measure proliferation of muscle nuclei. Mice were housed individually on a 12-hour light/dark cycle with access to food and water ad libitum. The animal care standards were followed by adhering to the recommendations for the care of laboratory animals as advocated by the American Association for Accreditation of Laboratory Animal Care and by following the policies and procedures detailed in the Guide for the Care and Use of Laboratory Animals as published by the United States Department of Health and Human Services and proclaimed in the Animal Welfare Act (PL89-544, PL91-979, and PL94-279). All experimental procedures carried approval by the Institutional Animal Care and Use Committee from West Virginia University.

\section{Hindlimb Suspension Unloading (HSU)}

HSU was conducted for 14 days as described previously [62,63]. Briefly, mice were suspended by adhering orthopedic tape to the tail which was attached to a metal swivel at the top of the cage, allowing for $360^{\circ}$ of rotation and movement. The mice were elevated to a torso angle of $30^{\circ}$ or lowest angle to keep hindlimbs elevated. Mice were monitored daily. The HSU+NoWR and HSU+WR mice were reloaded by removing the tail suspension and allowing normal cage 
ambulation. HSU+WR were additionally provided with a running wheel during reloading. Mice had unrestricted access to food and water throughout.

\section{Voluntary wheel running}

Following 14 days of normal cage activity or HSU, mice in the ControlWR and HSU+WR groups had their cages mounted with running wheels (cat. no. 0297-0050, Columbus Instruments, Columbus, Ohio). The number of rotations of the running wheels was recorded daily via a magnetic counter. Running wheel data was not collected on D14 and D21 as force and fatigue measurements were conducted on these days. The Control and HSU+NoWR mice were housed in identical cages but without running wheels.

In vivo isometric force measurements

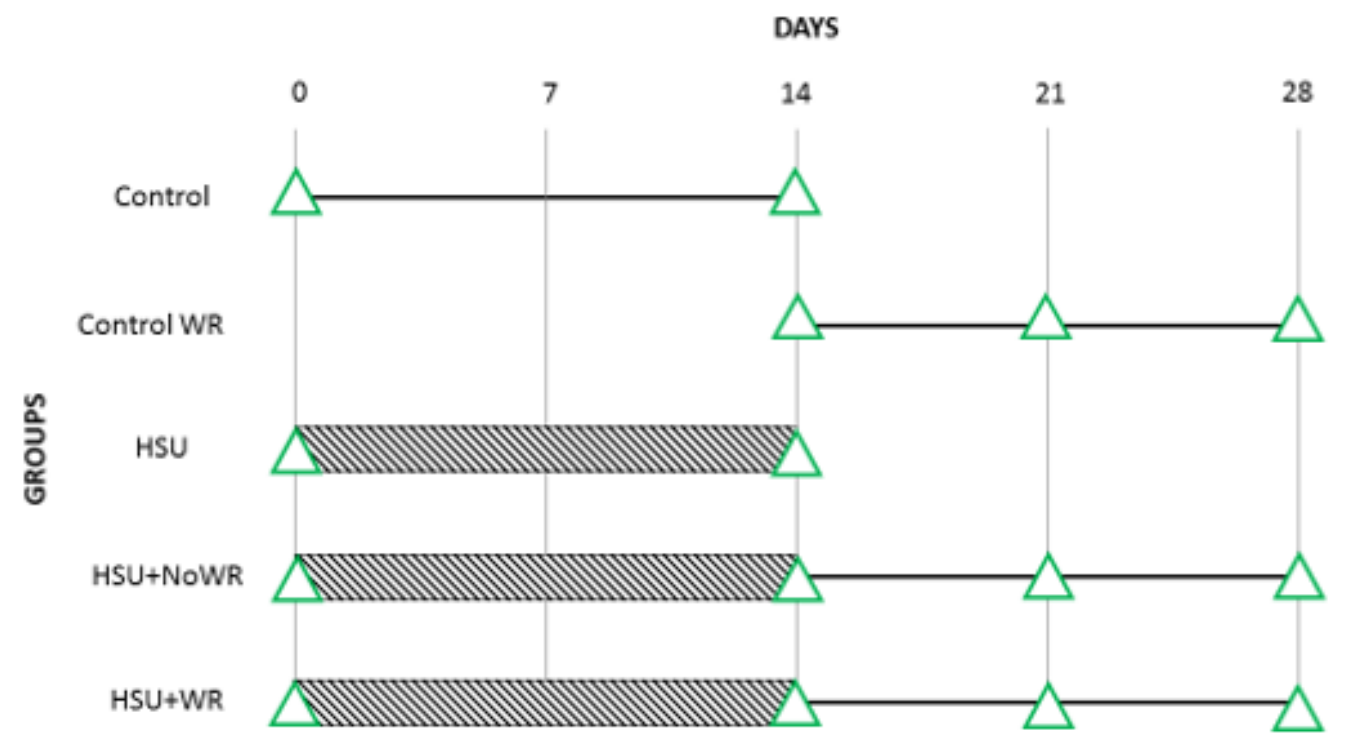

Figure 1: Research design. The above graphic shows the timeline of conducted experiments. Diagonal bars indicate HSU. Triangles indicate that in vivo maximum force and fatigue measurements were taken. Solid triangles indicate the date of euthanasia (following force and fatigue measurements). Exercised animals were introduced to running wheels on D14. 
The effects of the treatments on muscle function were measured by in vivo plantarflexor isometric maximal force and fatigue contractions as described previously [64]. Briefly, measurements were taken at D0, D14, D21, and D28 (Fig. 1). Animals were anesthetized with a mixture of $97 \%$ oxygen and $3 \%$ isoflurane gas and placed on a plate heated to $37^{\circ} \mathrm{C}$. The right hindlimb was then immobilized with the right ankle positioned at $90^{\circ}$ flexion and secured to the footplate of the dynamometer (Model 6350*358; Cambridge Technology Inc., Aurora Scientific Inc., ON, Canada). Subcutaneous platinum were placed on either side of the tibial nerve. Maximal force was measured by six sequential electrical impulses $(10 \mathrm{~Hz}, 25 \mathrm{~Hz}, 50 \mathrm{~Hz}, 75 \mathrm{~Hz}, 100 \mathrm{~Hz}$, and $125 \mathrm{~Hz}, 200 \mu$ s pulses) with a subsequent set of 180 contractions $(40 \mathrm{~Hz} ; .1$ s duration with $200 \mu \mathrm{s}$ pulse width) to measure rate of fatigue. Contractile data was analyzed offline (Dynamic Muscle Analysis software; Aurora Scientific).

\section{Body mass and tissue preparation}

Animals were weighed prior to in vivo force measurements (D0, D14, D21, and D28). Gastrocnemius muscles were surgically removed from the left hindlimb while the animals were deeply anesthetized. Following muscle harvesting, mice were euthanized by myocardial extraction. The gastrocnemius muscles were blotted to remove excess fluid and weighed. The left gastrocnemius muscle was mounted on cork at optimal length in optimal cutting temperature

(OCT) compound (Tissue-Tek; Andwin Scientific, Addison, IL), frozen in liquid nitrogen cooled methylbutane, and stored at $-80^{\circ} \mathrm{C}$ until sectioned for immunohistochemistry. Following sectioning, the left gastrocnemius muscle was removed from the OCT and stored for Western blotting. 


\section{Immunohistochemistry}

Frozen gastrocnemius and soleus tissue, which were mounted on a cork block with OCT compound, were cryostat sectioned (Leica CM3050 S, Wetzlar, Germany) at the mid-belly (10 $\mu \mathrm{m})$ onto charged microscope slides (Thermo Fischer Scientific, Waltham, Massachusetts), airdried, and stored at $-20^{\circ} \mathrm{C}$ until ready to be used. For BrdU/dystrophin detection, sections were fixed with methanol/acetone (1:1) and permeabilized with $0.4 \%$ Triton $\mathrm{X}$. Tissues were then incubated in $2 \mathrm{~N} \mathrm{HCl}$ for $1 \mathrm{hr}$ at $37^{\circ} \mathrm{C}$ and then neutralized with borate buffer. Background detection was blocked with 10\% normal goat serum (S-1000; Vector Laboratories, Burlingame, California) for $1 \mathrm{hr}$ prior to overnight incubation with primary mouse antibodies for BrdU (G3G4; Developmental Studies Hybridoma Bank, Iowa City, Iowa) and dystrophin (MANDYS8; Developmental Studies Hybridoma Bank) at $4^{\circ} \mathrm{C}$. After washing in PBS, tissues were incubated with goat anti-mouse antibodies for 2 hrs and mounted with coverslips. BrdU/dystrophin sections were imaged using a Nikon Eclipse E800 upright microscope and analyzed for BrdU and cell count using ImageJ software (National Institutes of Health, Bethesda, Maryland). For fiber type detection, tissue sections were blocked with $10 \%$ normal goat serum (S-1000; Vector Laboratories) for $1 \mathrm{hr}$ prior to overnight incubation of primary mouse antibodies for dystrophin (MANDYS8; Developmental Studies Hybridoma Bank) and the following myosin heavy chains (MHCs): MHC type I (BA-D5; Developmental Studies Hybridoma Bank), MHC type IIa (SC-71; Developmental Studies Hybridoma Bank), and MHC type IIb (BF-F3; Developmental Studies Hybridoma Bank). Sections were imaged using VS120 Virtual Slide Microscope (Waltham, Massachusetts) and analyzed for fiber CSA and count using NIS-Elements software.

Inflammatory response was scored using a published method [20,65]. Briefly, inflammation was scored in a blinded manner on a scale of $0-4: 0=$ no inflammation, $1=$ few 
scattered inflammatory cells, $2=$ clusters of inflammatory cells, $3=$ diffuse infiltrate of inflammatory cells, 4 = dense sheets of inflammatory cells, including lymphoid follicles. All BrdU-positive cells that were within dystrophin border were considered as inflammation for determining the inflammatory score. Data is presented in Appendix Figure 3.

\section{Western immunoblots}

Samples were prepared using procedures previously described [55,62]. Approximately seventy-five micrograms of muscle were homogenized in $200 \mu \mathrm{l}$ of ice-cold RIPA buffer ( $1 \%$ Triton $\mathrm{x}-100,150 \mathrm{mM} \mathrm{NaCl}, 5 \mathrm{mM}$ EDTA, $10 \mathrm{mM}$ Tris; $\mathrm{pH}$ 7.4), containing a protease inhibitor cocktail (cat. no. P8340; Sigma-Aldrich, St. Louis, Missouri), and phosphatase inhibitors (cat. no. P2850, P5726; Sigma-Aldrich). The homogenate was centrifuged at $1000 \mathrm{~g}$ for 10 minutes at $4^{\circ} \mathrm{C}$. The supernatant was measured for protein content (cat. no. 500-0116; Bio-Rad, Hercules, California). 50 micrograms of protein was loaded into each well of a 4-12\% gradient polyacrylamide gel (cat. no. NP0335BOX; Invitrogen, Carlsbad, California) and separated by routine sodium dodecyl sulfate-polyacrylamide gel electrophoresis (SDS-PAGE) for 1 hour at $150 \mathrm{~V}$. Proteins were transferred to a nitrocellulose membrane for 1.5 hours at $30 \mathrm{~V}$. Non-specific protein binding was blocked by incubating the membranes in 5\% nonfat milk in Tris-buffered saline containing $0.05 \%$ Tween 20 (TBST). The membranes were incubated (1:1000) overnight at $4^{\circ} \mathrm{C}$ with primary antibodies for Pax7 (ab187339, Abcam, Cambridge, United Kingdom), MyoD (cat. no. 554130, BD Pharmingen, Franklin Lakes, New Jersey), and GAPDH (cat. no. MA515738, Thermo Fischer Scientific). The membranes were then washed in TBST and incubated in appropriate dilutions of corresponding secondary antibodies (1:5000; diluted in 5\% nonfat milk) conjugated to horseradish peroxidase (Cell Signaling Technology, Boston, Massachusetts). The signals were developed using an enhanced chemiluminescent substrate (ca. no. 34075; Thermo 
Scientific) and autoradiographic signals were assessed using a G:Box Bioimaging System (Syngene, Frederick, Maryland). Band intensity was normalized to GAPDH using ImageJ software (NIH).

\section{Statistical Analysis}

Results are reported as mean \pm SE. Data were analyzed using GraphPad Prism software (GraphPad Software, La Jolla, California) using one-way or two-way ANOVA. Tukey post hoc analyses were performed if significance was detected. Significance was established at $P \leq 0.05$. In clearly noted instances, unpaired t-tests were used for less stringent comparison. 


\section{Chapter 4-Manuscript}

\section{Voluntary wheel running improves recovery from muscle disuse in mice}

Matthew J. Brooks ${ }^{1}$, Junaith S. Mohamed ${ }^{1}$, and Stephen E. Alway ${ }^{1}$

${ }^{1}$ Laboratory of Muscle Biology and Sarcopenia, West Virginia University School of Medicine, Morgantown, WV 26506 


\section{Abstract}

The reloading of atrophied muscles from weightlessness or disuse results in injury and prolonged recovery. Satellite cells, or muscle stem cells, have a key role in facilitating injuryinduced muscle repair but have not been shown to be required in muscle remodeling following atrophy. However, it has been less clear if low-impact exercise, such as voluntary wheel running, could provide a sufficient stimulus to enhance muscle recovery from atrophy through satellite cell activation. This study aimed to determine if voluntary wheel running improved recovery from muscle disuse following hindlimb suspension unloading (HSU), and if the recovery was associated with exercise-induced satellite cell activity. Young adult male and female C57BL/6 background mice ( $n=6 /$ group) were subjected to either 14 days of normal weight bearing, 14 days of HSU, 14 days of HSU + 14 days of re-ambulation, 14 days of voluntary wheel running, or 14 days of HSU +14 days of voluntary wheel running. Mice were given 5-bromo-2'-deoxyuridine (BrdU) in their drinking water during the final 14 days of the experiment to measure satellite cell proliferation in gastrocnemius muscle fibers. HSU significantly reduced in vivo maximal force and decreased the rate of fatigue in the plantarflexor muscles. Voluntary wheel running during reloading after HSU significantly improved resistance to fatigue, which was associated with significant increases in both muscle fiber cross sectional area (CSA) and an increased percentage of oxidative type IIA muscle fibers in the gastrocnemius muscle as compared to the mice recovering without exercise. BrdU positive nuclei that had proliferated and were located inside the muscle sarcolemma were identified by immunohistochemical labeling and quantified in tissue cross sections. Following HSU, wheel running mice had a significantly greater percentage of BrdU positive nuclei that were inside gastrocnemius muscle fibers. Western blot analysis showed HSU mice with wheel running had a higher MyoD to Pax7 ratio as compared to mice that did not exercise after HSU. Mice in the 
wheel running group had significantly improved fatigue resistance, a significantly increased oxidative fiber phenotype, and significantly increased fiber CSA as compared to non-exercised animals after HSU. These results indicate that voluntary wheel running increased satellite cell activity during the recovery phase following HSU and this was associated with improved recovery from muscle disuse. While satellite cells did not exhibit increased activity in passive recovery (non-wheel running), manipulating their activation through low-impact exercise appeared to enhance morphological recovery and improve muscle function.

Key Words: hindlimb suspension, satellite cells, voluntary wheel running, atrophy

\section{Introduction}

A high degree of muscle plasticity is evident in models of skeletal muscle atrophy and recovery [1-3]. Muscle atrophy, whether occurring from a primary cause such as unloading (i.e. microgravity, bed rest, or inactivity) or secondarily to changes in age, nutrition, or disease, results in an inherent loss of muscle function and strength that contributes to mobility impairment and decreased quality of life [1,3-7]. Understanding and determining therapeutic targets in the reloading phase following muscle wasting has critical implications for designing and developing treatment plans which can improve rehabilitation, reduce healthcare costs, and prevent further muscle damage.

Muscle disuse atrophy is characterized by decrements in muscle force, mass, and crosssectional area (CSA), as well as by a phenotypic shift of an oxidative myosin heavy chain (MHC) profile (type I and type IIa) to a more glycolytic composition (type IIb/x) [1,8,9]. Aerobic exercise induces a type IIb/x to type I/IIa fiber type switch in muscle and in some cases, increases CSA, 
and has been identified as a potential therapy to improve recovery from disuse atrophy [10-12]. However, atrophied muscles are susceptible to injury and exercising can cause further damage and delay recovery $[11,13,14]$. While 7 days of voluntary wheel running following hindlimb suspension unloading (HSU) was reported to recover muscle mass, CSA, and fatigue resistance, the lack of a control group during recovery raises the possibility that the results may not be due to the exercise per se [12]. Nevertheless, voluntary wheel running appeared to be a viable approach for investigating exercise during reloading without causing debilitating damage.

Multiple mechanisms affect HSU atrophy and recovery, and there is a lack of consensus of which mechanisms should be targeted $[2,10,15-18]$. One of the proposed mechanisms is satellite cell mediated recovery after muscle atrophy. Satellite cells are quiescent muscle stem cells that lie between the basal lamina and sarcolemma of myofibers and are known to be vital for muscle growth and repair [19]. Satellite cells have been established to be integral in the recovery from muscle damage [19] and several studies have shown similar roles during the management of unloading recovery $[20,21]$. However, muscle unloading has been shown to inhibit satellite cell proliferation [22] and a transgenic mouse model study convincingly demonstrated that the initial phase of recovery is not dependent on stimulating satellite cell proliferation [23]. Nevertheless, it is unknown if satellite cell proliferation would affect early recovery from muscle disuse.

The primary aim of the present study was to determine if voluntary wheel running improved functional and morphological recovery from muscle disuse following hindlimb suspension unloading (HSU). Voluntary wheel running has been shown to increase satellite cell proliferation [24-26]. Therefore, the secondary aim of the study was to evaluate if voluntary wheel running during reloading provided a sufficient stimulus to activate satellite cells and enhance muscle recovery after HSU. 


\section{Material and Methods}

Mouse Model

Young adult (4-5 months of age), male and female C57BL/6 mice were obtained from Jackson Labs and randomly assigned to five groups $(n=6)$ : 14 days of normal weight bearing (Control), 14 days of HSU (HSU), 14 days of HSU + 14 days of re-ambulation (HSU+NoWR), 14 days of voluntary wheel running (ControlWR), or 14 days of HSU + 14 days of voluntary wheel running (HSU+WR). 5-bromo-2'-deoxyuridine (BrdU) was provided in the drinking water $(0.8$ $\mathrm{mg} / \mathrm{ml}$ ) during the final 14 days of the experiment to measure cell proliferation. Mice were housed individually on a 12-hour light/dark cycle with access to food and water ad libitum. The animal care standards were followed by adhering to the recommendations for the care of laboratory animals as advocated by the American Association for Accreditation of Laboratory Animal Care and by following the policies and procedures detailed in the Guide for the Care and Use of Laboratory Animals as published by the United States Department of Health and Human Services and proclaimed in the Animal Welfare Act (PL89-544, PL91-979, and PL94-279). All experimental procedures carried approval by the Institutional Animal Care and Use Committee from West Virginia University.

\section{Hindlimb Suspension Unloading (HSU)}

HSU was conducted for 14 days as described previously [27,28]. Briefly, the hindlimb muscles of mice unloaded by adhering orthopedic tape to the tail which was attached to a metal swivel at the top of the cage, allowing for $360^{\circ}$ of rotation and movement. The mice were elevated to a torso angle of $30^{\circ}$ or lowest angle to keep hindlimbs elevated. Mice were monitored daily. The HSU+NoWR and HSU+WR mice were reloaded by removing the tail suspension and 
allowing normal cage ambulation. HSU+WR were additionally provided with a running wheel during reloading. Mice had unrestricted access to food and water throughout the HSU and recovery periods.

Voluntary wheel running

Following 14 days of normal cage activity or HSU, mice in the ControlWR and HSU+WR groups had their cages mounted with running wheels (cat. no. 0297-0050, Columbus Instruments, Columbus, Ohio). The Control and HSU+NoWR mice were housed in identical cages but without running wheels.

In vivo isometric force measurements

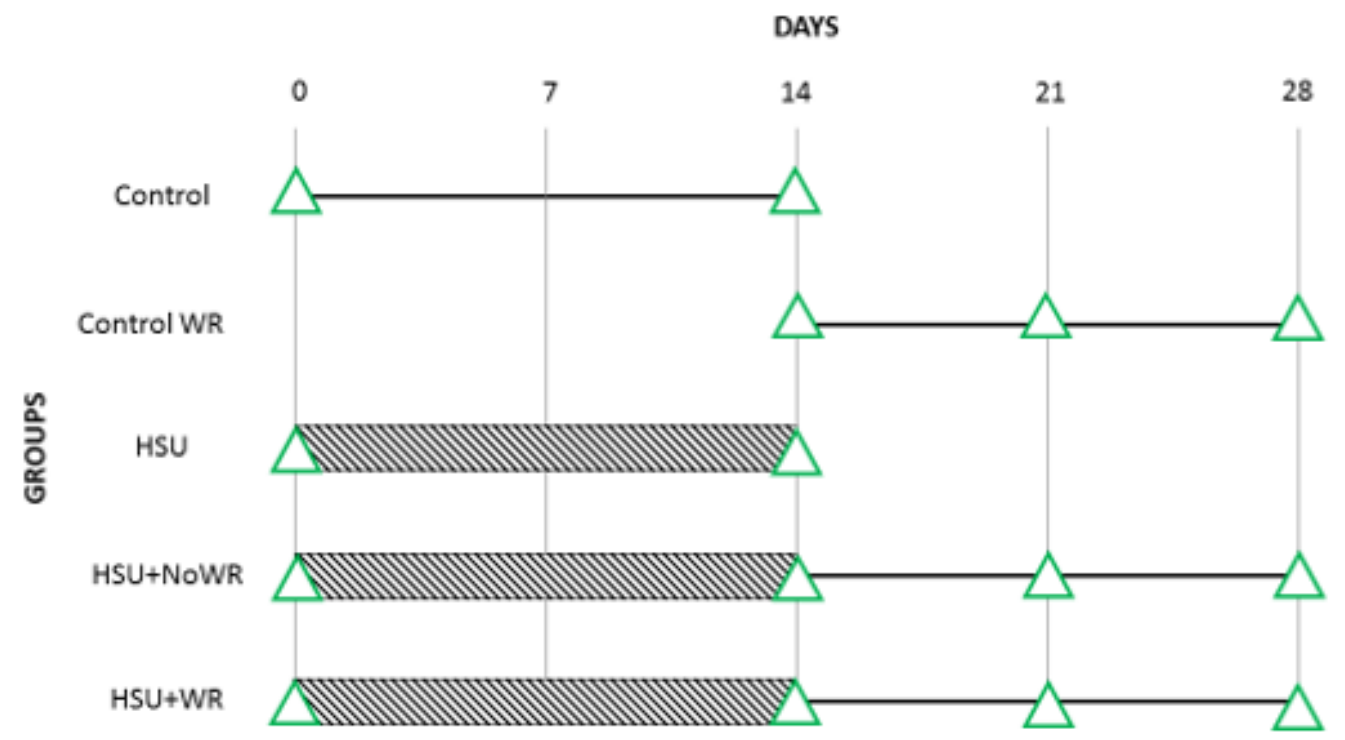

Figure 1: Research design. The above graphic shows the timeline of conducted experiments. Diagonal bars indicate HSU. Triangles indicate that in vivo maximum force and fatigue measurements were taken. Solid triangles indicate the date of euthanasia (following force and fatigue measurements). Exercised animals were introduced to running wheels on D14.

The effects of the treatments on muscle function were measured by in vivo plantarflexor isometric maximal force and fatigue contractions as described previously [29]. Briefly, 
measurements were taken at day 0 (D0), D14, D21, and D28 (Fig. 1). Animals were anesthetized with a mixture of $97 \%$ oxygen and $3 \%$ isoflurane gas and placed on a plate heated to $37^{\circ} \mathrm{C}$. The right hindlimb was then immobilized with the right ankle positioned at $90^{\circ}$ flexion and secured to the footplate of the dynamometer (Model 6350*358; Cambridge Technology Inc., Aurora Scientific Inc., ON, Canada). Subcutaneous platinum were placed on either side of the tibial nerve. Maximal force was measured by six sequential electrical impulses $(10 \mathrm{~Hz}, 25 \mathrm{~Hz}, 50 \mathrm{~Hz}, 75 \mathrm{~Hz}$, $100 \mathrm{~Hz}$, and $125 \mathrm{~Hz})$ with a subsequent set of 180 contractions $(40 \mathrm{~Hz} ; .1$ s duration with $200 \mu$ s pulse width) to measure rate of fatigue. Contractile data was analyzed offline (Dynamic Muscle Analysis software; Aurora Scientific).

\section{Body mass and tissue preparation}

Mice were weighed prior to in vivo force measurements (D0, D14, D21, and D28). Gastrocnemius muscles were surgically removed from the left hindlimb while the animals were deeply anesthetized. Following muscle harvesting, mice were euthanized by myocardial extraction. The gastrocnemius muscles were blotted to remove excess fluid and weighed. The left gastrocnemius muscle was mounted on cork at optimal length in optimal cutting temperature (OCT) compound (Tissue-Tek; Andwin Scientific, Addison, IL), frozen in liquid nitrogen cooled methylbutane, and stored at $-80^{\circ} \mathrm{C}$ until sectioned for immunohistochemistry. Following cryosectioning, the left gastrocnemius muscle was removed from the OCT and processed for Western blotting.

\section{Immunohistochemistry}

Frozen $10 \mu \mathrm{m}$ sections were obtained on a cryostat (Leica CM3050 S, Wetzlar, Germany) from the mid-belly of the gastrocnemius muscles. Tissue sections were placed on charged 
microscope slides (Thermo Fischer Scientific, Waltham, Massachusetts), air-dried, and stored at $20^{\circ} \mathrm{C}$ until ready to be used. For BrdU/dystrophin detection, the sections were fixed in methanol/acetone (1:1) and permeabilized with $0.4 \%$ Triton X. Tissues. The sections were washed in phosphate buffered saline (PBS) then incubated in $2 \mathrm{~N} \mathrm{HCl}$ for $1 \mathrm{hr}$ at $37^{\circ} \mathrm{C}$ and finally neutralized with borate buffer. Non-specific protein detection was blocked with $10 \%$ normal goat serum (S-1000; Vector Laboratories, Burlingame, California) for 1hr prior to overnight incubation of primary mouse antibodies for BrdU (G3G4; Developmental Studies Hybridoma Bank, Iowa City, Iowa) and dystrophin (MANDYS8; Developmental Studies Hybridoma Bank) at $4^{\circ} \mathrm{C}$. After washing in PBS, tissues were incubated with goat anti-mouse antibodies for $2 \mathrm{hrs}$ and mounted on coverslips. BrdU/dystrophin sections were imaged using a Nikon Eclipse E800 upright microscope and analyzed for BrdU and cell count using ImageJ software (National Institutes of Health, Bethesda, Maryland). For fiber type detection, sections were blocked with $10 \%$ normal goat serum (S-1000; Vector Laboratories) for $1 \mathrm{hr}$ prior to overnight incubation of primary mouse antibodies for dystrophin (MANDYS8; Developmental Studies Hybridoma Bank) and the following myosin heavy chains (MHCs): MHC type I (BA-D5; Developmental Studies Hybridoma Bank), MHC type IIa (SC-71; Developmental Studies Hybridoma Bank), and MHC type IIb (BF-F3; Developmental Studies Hybridoma Bank). Sections were imaged using VS120 Virtual Slide Microscope (Waltham, Massachusetts) and analyzed for fiber CSA and count using NIS-Elements software.

As HSU and voluntary wheel running elicit greater responses in oxidative fiber types, we identified areas within the gastrocnemius muscle cross sections that contained higher oxidative fiber compositions as described earlier [30]. Rather than regional selections of fibers, the entire gastrocnemius was measured in other assays. 


\section{Western immunoblots}

Tissue samples were prepared using procedures previously described [21,27]. Approximately 75 micrograms of muscle was homogenized in $200 \mu$ l of ice-cold RIPA buffer (1\% Triton $\mathrm{x}-100,150 \mathrm{mM} \mathrm{NaCl}, 5 \mathrm{mM}$ EDTA, $10 \mathrm{mM}$ Tris; $\mathrm{pH}$ 7.4), containing a protease inhibitor cocktail (cat. no. P8340; Sigma-Aldrich, St. Louis, Missouri), and phosphatase inhibitors (cat. no. P2850, P5726; Sigma-Aldrich). The homogenate was centrifuged at 1000g for 10 minutes at $4{ }^{\circ} \mathrm{C}$. The supernatant was collected and measured for protein content (cat. no. 500-0116; BioRad, Hercules, California). 50 micrograms of protein was loaded into each well of a 4-12\% gradient polyacrylamide gel (cat. no. NP0335BOX; Invitrogen, Carlsbad, California) and separated by routine sodium dodecyl sulfate-polyacrylamide gel electrophoresis (SDS-PAGE) for 1 hour at $150 \mathrm{~V}$. Proteins were transferred to a nitrocellulose membrane for 1.5 hours at $30 \mathrm{~V}$. Nonspecific protein binding was blocked by incubating the membranes in 5\% nonfat milk in Trisbuffered saline containing $0.05 \%$ Tween 20 (TBST). The membranes were incubated (1:1000) overnight at $4^{\circ} \mathrm{C}$ with primary antibodies for Pax7 (ab187339, Abcam, Cambridge, United Kingdom), MyoD (cat. no. 554130, BD Pharmingen, Franklin Lakes, New Jersey), and GAPDH (cat. no. MA5-15738, Thermo Fischer Scientific). The membranes were then washed in TBST and incubated in the appropriate secondary antibodies (1:5000; diluted in 5\% nonfat milk) that were conjugated to horseradish peroxidase (Cell Signaling Technology, Boston, Massachusetts).The signals were developed using an enhanced chemiluminescent substrate (ca. no. 34075; Thermo Scientific) and autoradiographic signals were assessed using a G:Box Bioimaging System (Syngene, Frederick, Maryland). Band intensity was normalized to GAPDH using ImageJ software (NIH). 


\section{Statistical Analysis}

The results are reported as mean \pm SE. Data were analyzed using GraphPad Prism software (GraphPad Software, La Jolla, California) using one-way or two-way ANOVA. Tukey post hoc analyses were performed if significance was detected. Significance was established at $P \leq 0.05$. In a few clearly noted instances, unpaired t-tests were used for less stringent comparison.

\section{Results}

Voluntary wheel running

Voluntary wheel running was measured daily as km run beginning on D15 (Fig. 2). Running occurred nearly exclusively during the $12 \mathrm{hr}$ dark-cycle. Data were excluded from D15 and D22 as in vivo maximum force and fatigue measurements were taken during the preceding light-cycle (D14, D21). The HSU+WR group ran only $56 \%$ of the distance that ControlWR mice

ran during D16-18, although this did not reach statistical significance $(P=0.13)$. This observation was consistent with other data for reloading atrophied muscles in mice [12]. Following the initial reloading, the HSU+WR group ran equidistant to the ControlWR group, consistent with previous studies [12].

\section{Body and gastrocnemius mass}

Two weeks of HSU resulted in a significant decrease in body mass (BM) (Fig. 3A) and gastrocnemius mass (Fig. 3B). BM was normalized to the initial $\mathrm{BM}$ value $\left(\mathrm{BM}_{0}\right)$ and gastrocnemius mass was normalized to terminal BM. There was no detectable change in BM or gastrocnemius mass from initial values by D7 of recovery for both the HSU+NoWR and HSU+WR 


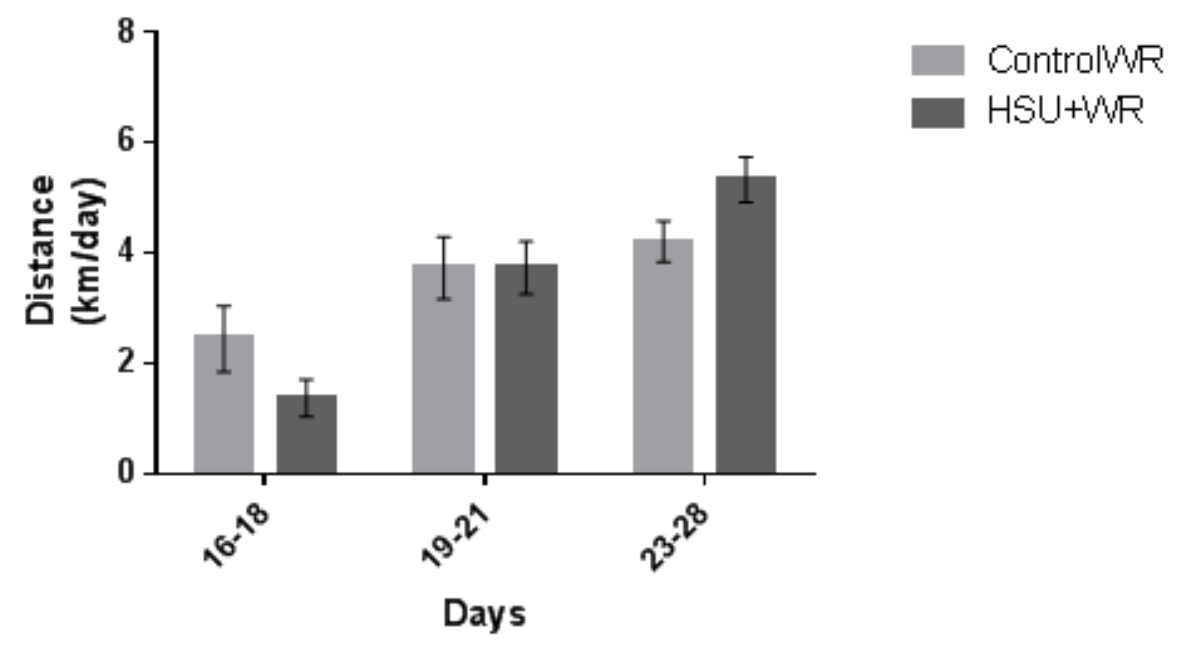

Figure 2: Voluntary wheel running. Average wheel running for ControlWR and HSU+WR. Mice were given access to running wheels D15-D28 following 14 days of normal cage activity or HSU. Data is excluded from $\mathrm{D} 15$ and D22 due to in vivo force testing. Values are presented as mean \pm SE. Statistical analysis was performed using one-way ANOVA with Tukey post-hoc test. Significance was set at $P \leq 0.05$.

groups. Voluntary wheel running (ControlWR) had a statistically significant increase in body mass compared to the Control group. The gastrocnemius mass decreased in the ControlWR group, although this was likely a result of the normalization to body mass.

There were no significant differences between male and female mice within any of the groups (Appendix Fig. 1).

Maximum force and fatigue rate

Maximum force and fatigue were measured in vivo. Maximum force is presented as a percentage of initial tetanic maximum force output $\left(\mathrm{Fo}_{\mathrm{O}}\right)$ (Fig. 4A). Maximum force decreased $27 \%$ following 2 weeks of HSU but there was no statistically significant difference between control and recovery measurements. Although not statistically significant, the $20 \%$ decrease ( $P=0.11$ vs. Control) in maximum tetanic force of the HSU+WR group at D7 of recovery suggests that reloading with voluntary wheel running delays the initial recovery of maximum force. 

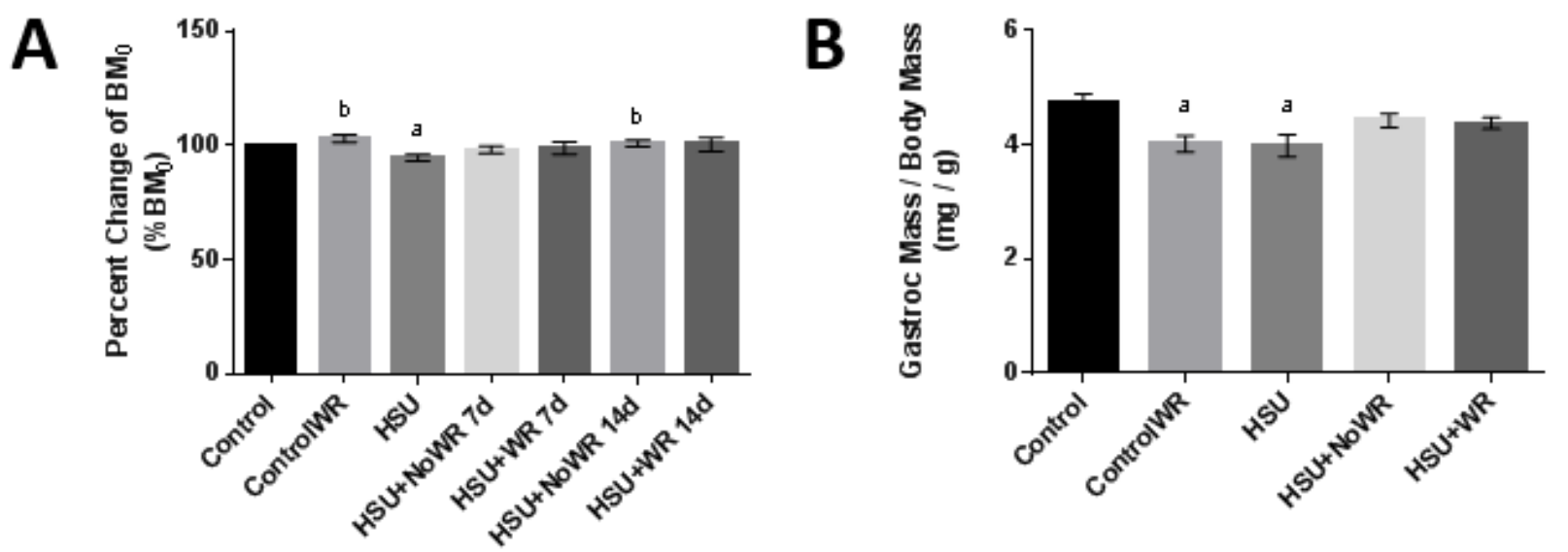

Figure 3: Body and gastrocnemius mass. A: Body mass (BM) normalized to initial $B M\left(B M_{0}\right)$. 2wk HSU resulted in a decreased BM. BM recovered by D7 in both $\mathrm{HSU}+\mathrm{NoWR}$ and HSU+WR. B: Gastrocnemius mass normalized to BM. 2 wk HSU resulted in decreased gastrocnemius mass that recovered by D7 in both HSU+NoWR and HSU+WR. Values are presented as mean \pm SE. ${ }^{a} P \leq 0.05$ vs. Control; ${ }^{b} P \leq 0.05$ vs. HSU. Statistical analysis was performed using one-way ANOVA with Tukey post-hoc test.C
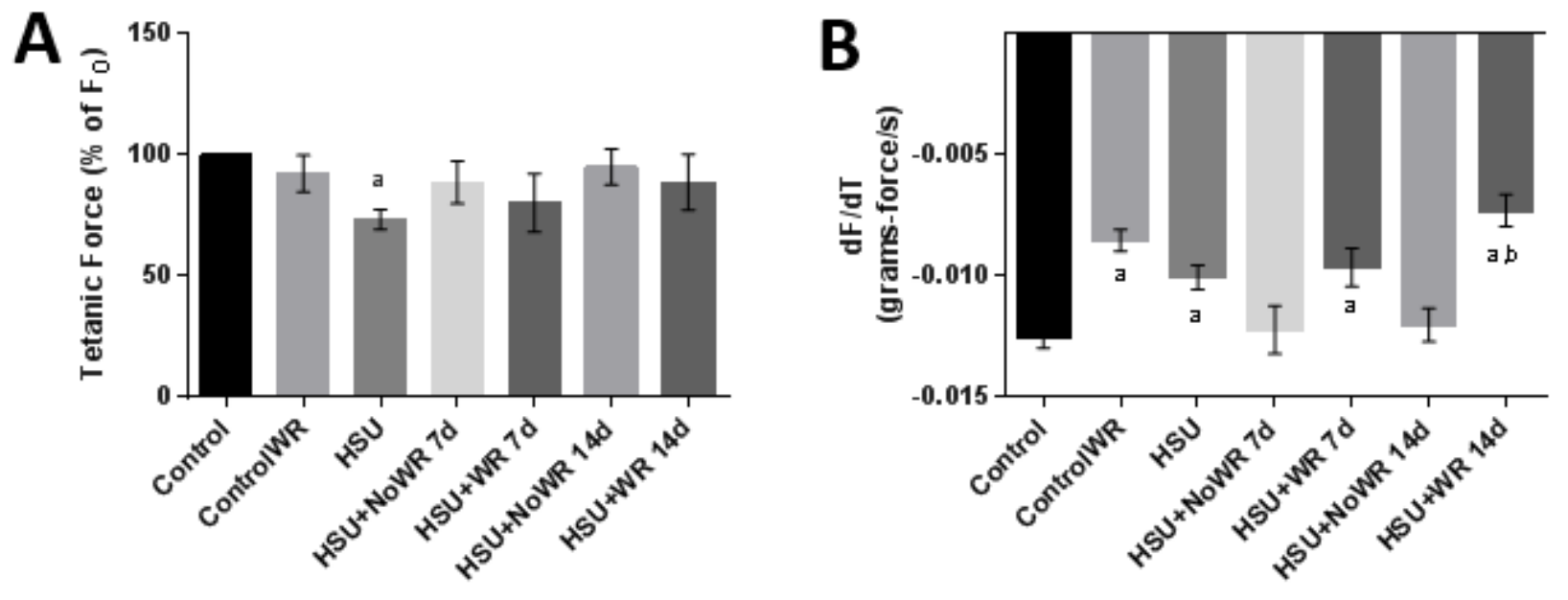

Figure 4: Maximum tetanic force and fatigue rate. A: Tetanic force presented as a percentage of initial tetanic maximum force output $\left(\mathrm{F}_{0}\right)$. B: Fatigue rate presented as the rate of change from maximum force to final fatigue output. Values are presented as mean $\pm \mathrm{SE}$. ${ }^{a} P \leq 0.05$ vs. Control; ${ }^{b} P \leq 0.05$ vs. HSU. Statistical analysis was performed using one-way ANOVA with Tukey post-hoc test.

The rate of fatigue in the current study is presented as the rate of change from maximum force to force that was generated at the final contraction in the fatigue test (Fig. 4B). A decrease in the fatigue rate is interpreted as an improvement of fatigue resistance. The ControlWR group 
significantly decreased fatigue rate by $32 \%$ after 14 days of wheel running. Interestingly, the HSU group also significantly decreased fatigue rate by $20 \%$. The HSU+NoWR group returned to preHSU rates by D7 of recovery and did not change after by D14. Meanwhile, the HSU+WR group fatigue rate remained unchanged after the first 7 days of reloading, but the fatigue rate continued to decrease through the second week of reloading. By D14 of recovery, the HSU+WR group fatigue rate was $42 \%$ less than the Control group. The ANOVA did not detect significance between the HSU+WR group and the ControlWR at D14 of recovery, but the data trend is indicative of a protective measure against the underlying atrophy mechanism that reduced fatigue resistance.

Fiber type frequency and cross sectional area

HSU has been reported to cause oxidative-to-glycolytic fiber type switching as well as targeted atrophy of oxidative fibers [1]. These effects were evaluated through immunohistochemical staining of myosin heavy chain (MHC) (Fig.5).

Type I fiber percentage showed no difference between groups using two-way ANOVA. However, t-tests showed statistical decreases in type I fibers of $56 \%$ from Control to HSU $(P=0.05)$ and of $73 \%$ from Control to HSU+WR $(P=0.01)$. Type IIa) fiber frequency analysis (as measured using two-way ANOVA and post-hoc Tukey test) showed that the ControlWR group had a significant increase of $66 \%(P<0.05)$ compared to the Control group.

Furthermore, the HSU+WR and ControlWR groups had significantly elevated frequencies of type IIa fibers compared to the HSU group (95\% and $139 \%, P<0.05$ respectively) and the HSU+NoWR group (60\% and 97\%, respectively). Type IIb/x fiber frequencies were inversely related to type IIa changes. The ControlWR and HSU+WR group had significantly fewer type 


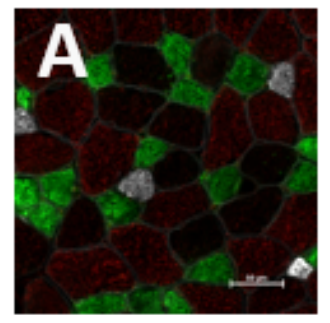

Control

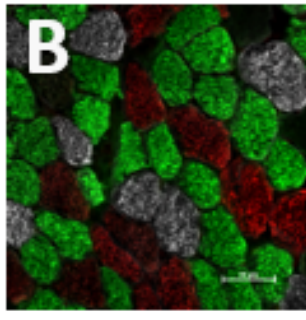

ControlWR

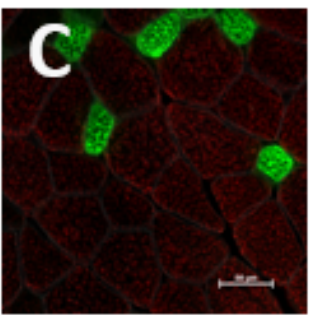

HSU

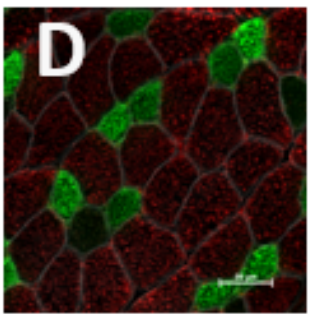

HSU+NoWR

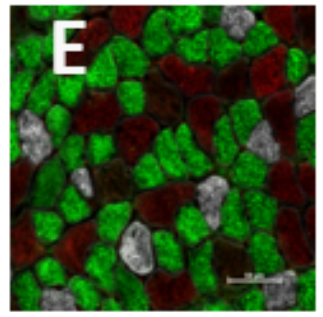

HSU+WR
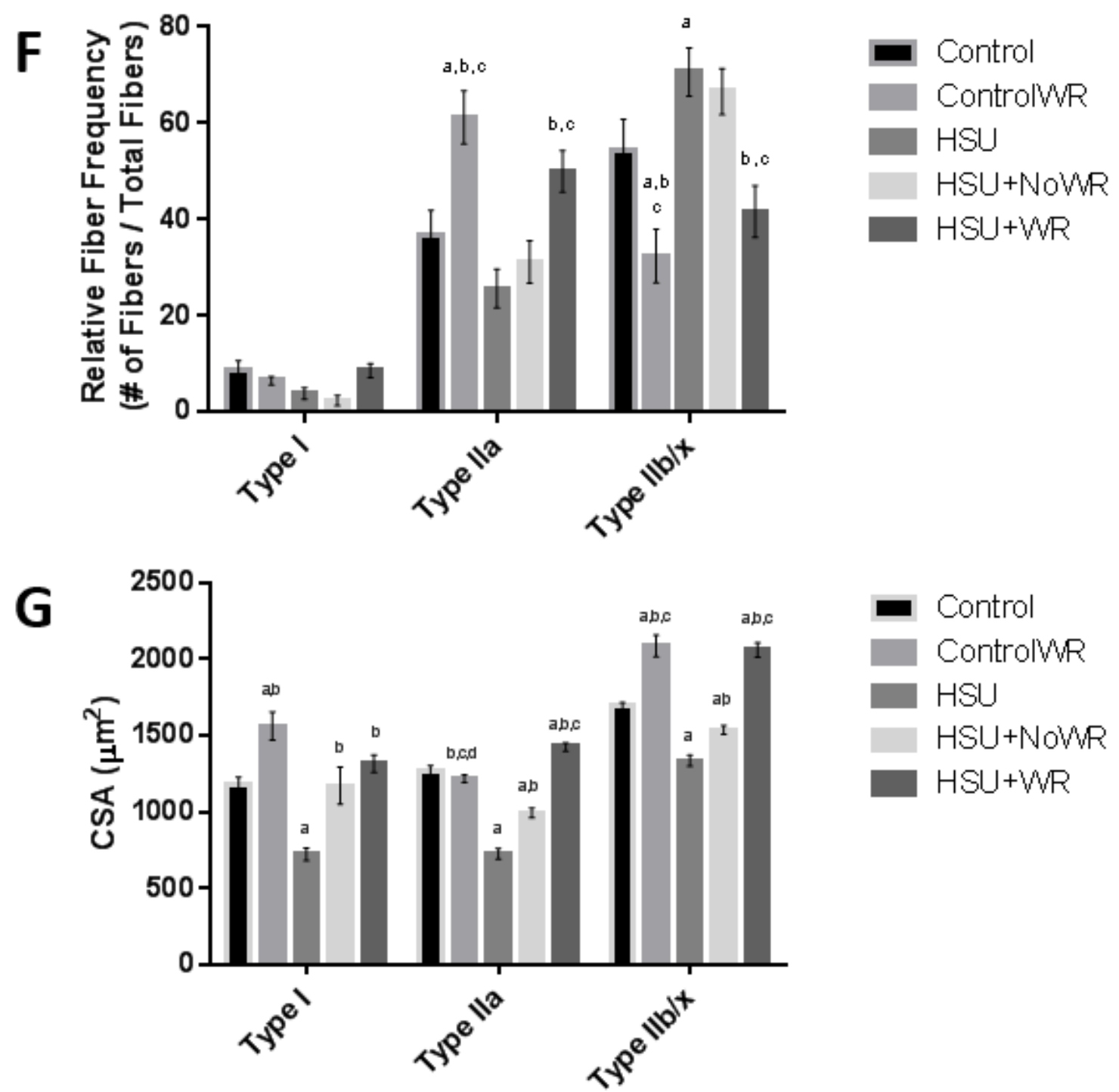

Figure 5: Fiber type frequency and CSA. A-E: Representative images of gastrocnemius muscle cross sections. Sections were immunohistochemically stained for myosin heavy chain (MHC): MHC Type I (white), MHC Type IIa (green), MHC Type IIb (red), and MHC Type IIx (unstained/black).

F: Quantification of relative fiber frequency. Percentages are expressed as number per muscle. G: Quantification of cross sectional area (CSA). Values are presented as mean $\pm \mathrm{SE}$. ${ }^{\mathrm{P}} P \leq 0.05$ vs. Control; ${ }^{b} P \leq 0.05$ vs. HSU; $P \leq 0.05$ vs. HSU+NoWR; $P \leq 0.05$ vs. HSU+WR. Statistical analysis was performed using two-way ANOVA with Tukey post-hoc test. 
$\mathrm{IIb} / \mathrm{x}$ fiber than Control $(-41 \%$ and $-24 \%, P<0.05$ respectively), HSU $(-54 \%$ and $-41 \%, P<0.05$ respectively), and HSU+NoWR $(-49 \%$ and $-38 \%, P<0.05$ respectively).

Compared to the Control group, unloading-induced atrophy resulted in a significant decrease of type I $(-39 \%, P<0.05)$, IIa $(-43 \%)$, and IIb/x $(-21 \%, P<0.05)$ fiber CSA (Fig. 5G). Normal ambulation during recovery (HSU+NoWR) significantly improved the CSA in all fiber types, but both IIa and IIb/x fibers remained significantly smaller $(P<0.05)$ than Control fiber sizes. The wheel running control (ControlWR) group had a significantly greater type I $(31 \%, P<0.05)$ and IIb/x $(23 \%, P<0.05)$ fiber CSA compared to Control mice. Of particular interest is that the HSU mice with 2 weeks of voluntary wheel running (HSU+WR) had significantly larger type IIa (43\%, $P<0.05)$ and type $\mathrm{IIb} / \mathrm{x}(34 \%, P<0.05)$ fibers compared to mice that did not have access to wheel running during recovery (HSU+NoWR).

\section{Satellite Cell Activity}

Satellite cell proliferation was assessed by measuring BrdU incorporation into myonuclei (Fig. 6), Pax7 expression (Fig. 7A), and MyoD expression (Fig. 7B). BrdU is a thymidine analog that is used to detect cell proliferation. When activated, satellite cells can proliferate, differentiate, and fuse with existing myofibers, leading to myonuclear accretion [31]. In this study, voluntary wheel running increased BrdU incorporation 2-fold compared to the Control group, consistent with previously published data [24]. Hindlimb suspension decreased cell proliferation and BrdU incorporation into satellite cells was rarely found. Reloading the muscle following hindlimb suspension significantly increased BrdU levels compared to the Control (HSU+NoWR: 3-fold increase, $P<0.05$; HSU+WR: 6-fold increase, $P<0.05)$. The HSU+WR group had the greatest incorporation of nuclear BrdU with a 6-fold increase $(P<0.05)$ compared to the Control group and 2-fold increase $(P<0.05)$ compared to the HSU+NoWR group. 


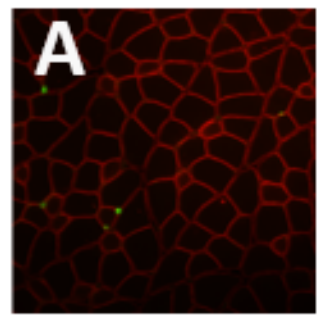

Control

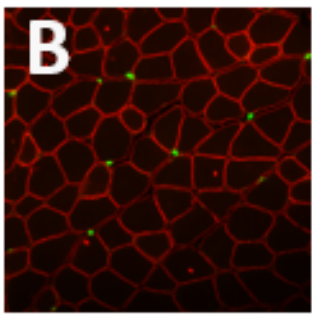

ControlWR

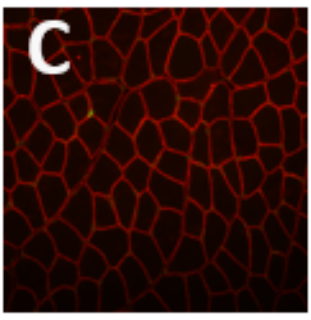

HSU

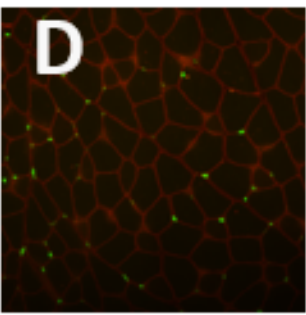

HSU+NoWR

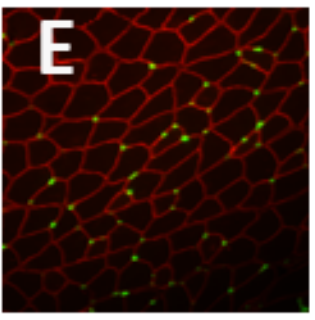

HSU+WR

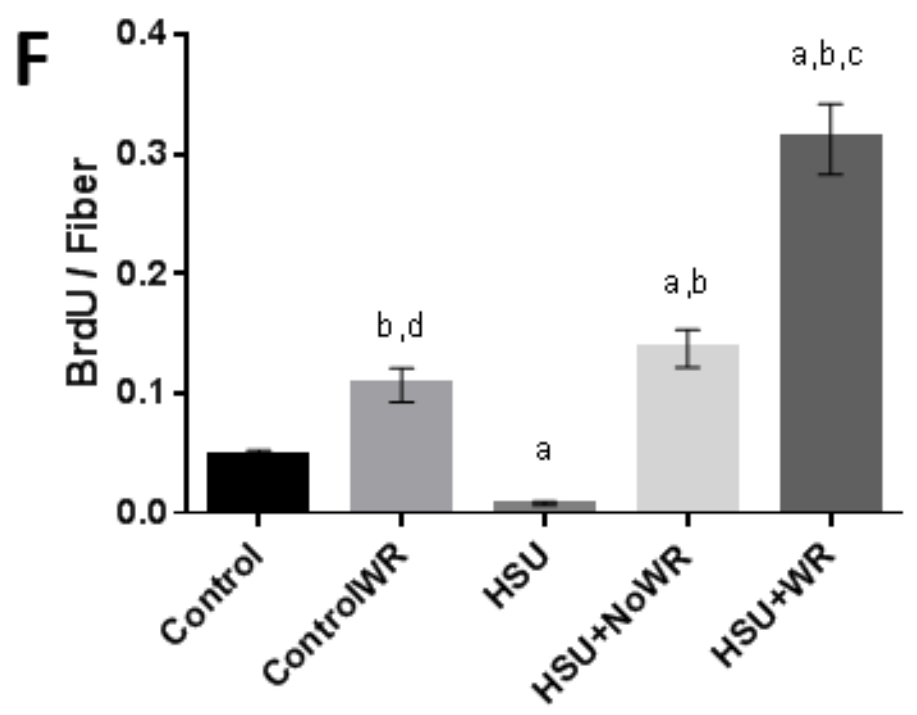

Figure 6: BrdU labeled nuclei. A-E: Representative images of gastrocnemius muscle cross sections. Sections were immunohistochemically stained for 5-bromo-2'-deoxyuridine (BrdU) (green) and dystrophin (red) F: Quantification of BrdU per fiber. Only BrdU labeled nuclei that lie fully within the dystrophin border were counted. Values are presented as mean $\pm \mathrm{SE}$. ${ }^{a} P \leq 0.05$ vs. Control; ${ }^{b} P \leq 0.05$ vs. HSU; $\mathrm{c} P \leq 0.05$ vs. HSU+NoWR; $d P \leq 0.05$ vs. HSU+WR. Statistical analysis was performed using oneway ANOVA with Tukey post-hoc test.

Pax7 is expressed by quiescent and non-differentiating satellite cells, and for this reason it is an effective marker for satellite cell quantity. Pax7 has also been shown to indirectly interfere with MyoD expression [32]. Accordingly, increased quantities of Pax7 is indicative of larger satellite cell populations, while a loss of Pax 7 expression and an increase in MyoD expression indicates satellite cell differentiation. In this study, Western blot analysis was used to measure both Pax7 and MyoD expression (Fig. 7) in muscle homogenates. Due to the presence of variance in the data, a two-way ANOVA analysis did not detect any significant differences. However, it is likely that that a larger group size would have produced significant differences between the 
experimental groups. Therefore, we analyzed group differences between MyoD and Pax 7 (Fig. 7) using unpaired t-tests $(P \leq 0.1)$.

Pax7 expression was unchanged following HSU and during reloading without the use of running wheels (HSU+NoWR). However, the HSU+NoWR group had a large variance due to the presence of two groupings of expression, one concentrated at significantly increased levels of Pax7 and one cluster that remained at levels similar to the Control group. This could be an indication that at D14, satellite cells may have been proliferating in a secondary phase of recovery in muscles of some mice while other mice may have still been in the initial, non-satellite mediated recovery stage at the point that the study was terminated. Although not achieving statistical significance, the ControlWR mice increased Pax7 expression (2-fold) due to wheel running compared to controls, corresponding with previous studies that found wheel running increases satellite cell proliferation [25]. The HSU+WR group had low expression of Pax7 and this was consistently found to be significantly lower than the protein abundance for the HSU+NoWR group.

MyoD protein abundance was significantly greater in the ControlWR (3.5-fold, $P<0.05)$, HSU+NoWR (6-fold, $P<0.05$ ), and HSU+WR (12-fold, $P<0.05$ ) groups. MyoD protein abundance was not statistifcally different between the HSU+NoWR and HSU+WR. This was likely due to a large degree of variance in the HSU+WR group. However, the increased incorporation of BrdU in nuclei of the HSU+WR group, along with decreased expression of Pax7, and increased expression of MyoD is supportive of the hypothesis that satellite cells can be activated and incorporated into myofibers in mice that have access to wheel running during reloading. 

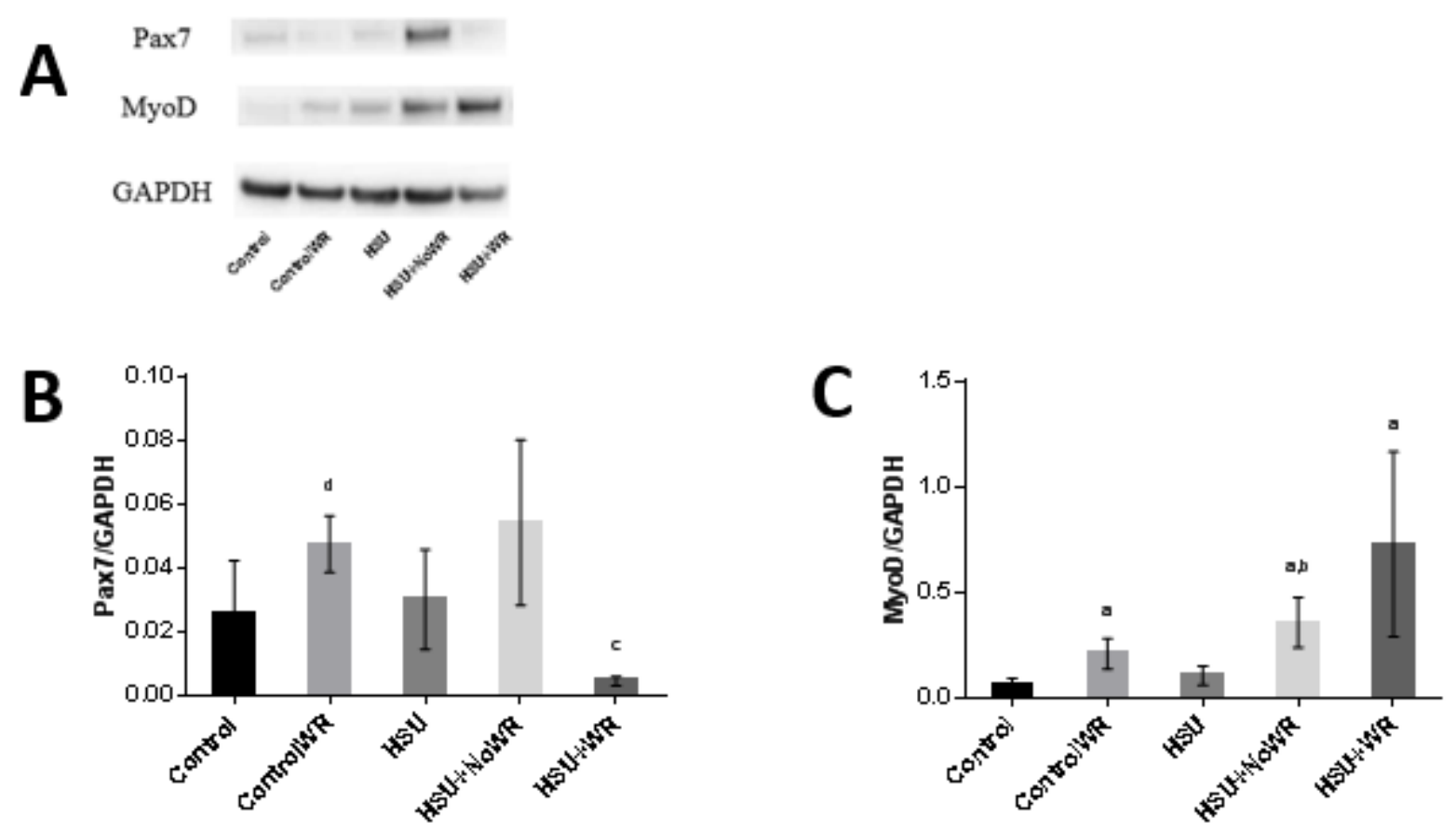

Figure 7: MyoD and Pax7 expression. A: Representative image of Western blot. B: Quantification of Pax7 expression normalized to GAPDH. C: Quantification of MyoD expression normalized to GAPDH. Values are presented as mean $\pm \mathrm{SE}$. ${ }^{\mathrm{a}} P \leq 0.05$ vs. Control; ${ }^{b} P \leq 0.05$ vs. HSU; $c P \leq 0.05$ vs. HSU+NoWR; ${ }^{d} P \leq 0.05$ vs. HSU+WR. Statistical analysis was performed using unpaired t-tests significance at $P \leq 0.1$.

\section{Discussion}

There is currently no treatment to prevent muscle atrophy from disuse as modeled by HSU. As such, there is a need for improving the recovery process. Endurance exercise has been identified as a potential therapy, as its many adaptations provide opposing effects to unloading $[11,12]$. In rats, treadmill training was shown to have some long term benefits, but at the cost of muscle injury during early reloading [11]. Voluntary wheel running for 7 days following HSU was shown to recover performance to a level that is comparable to non-suspended mice who had access to voluntary wheel running for 7 days [12]. 
Voluntary wheel running minimized damage to atrophied muscles

Mice that were suspended ran less $(P=0.13)$ for the first 3 days of recovery than nonsuspended mice (Fig. 2). This initial self-withdrawal from exercise illustrates the advantage of allowing the mice to determine what level of exercise they can handle to presumably eliminate any experimentally induced injury, such as that seen in treadmill training [11]. It has been suggested that factors that influence the mice to initially limit running may include unaccustomed weight bearing, soreness, and or transient injury [12]. The only non-beneficial effect of wheel running during reloading was evidenced by an $8 \%$ difference in maximum force recovery at D7 $(P=0.58$ using t-test). At D7 of reloading, both mice with and without access to wheel running regained the HSU-related body weight loss and fatigue resistance was improved in mice with wheel running. Taken together, there is no indication that there was any debilitating injury as result of the wheel running. If transient injury did occur, it is important to note that wheel running allowed mice to exercise at a rate that did not further exacerbate the injury.

\section{Voluntary wheel running improved functional recovery}

The primary purpose of this study was to determine if voluntary wheel running improved functional recovery during the reloading of atrophied muscles. This analysis was based on three factors: muscle mass, maximal force, and fatigue rate. Muscle mass and maximal force production were not significantly affect by the use of the running wheels. This was expected because the aerobic nature of wheel running exercise is a low impact activity that is devoid of significant injury.

The methods of measuring fatigue in HSU studies is highly variable, with each method being able to determine only specific aspects of the complex physiological processes that are responsible for fatigue. To the best of our knowledge, the only previous study that has used wheel 
running during HSU recovery model used "rate of fatigue" (a measure of fatigue resistance) to analyze fatigue [12]. The increased fatigue resistance measured in the present study is consistent with the only other HSU study with voluntary wheel running during recovery [12]. This improved fatigue resistance, which contrasts data gathered by ex vivo fatigue analysis [1], was proposed to be a pseudo effect caused by the muscle continuing to produce high levels of energy substrate even though there is a reduction in contractile proteins [12].

A novel finding from this study is that wheel running improved the fatigue rate of hindlimb muscles in mice during recovery. It was recently reported that in situ fatigue resistance of the soleus worsens following HSU for at least 15 days, before eventually fully recovering fatigability by 60 days of recovery via normal ambulation after HSU [1]. Our results demonstrate that access to wheel running decreases fatigue rate after 7 days of recovery, which is consistent published data [12], and continues to decrease fatigue through the 14 measured days of recovery, representing a significant improvement as compared to no running after HSU.

Voluntary wheel running improves recovery from selective atrophy of oxidative fibers

At a morphological level, the beneficial effects of wheel running become even clearer. The selective atrophy to oxidative fibers (type I and IIa) was consistent with published data (Fig. 5) $[1,9,12]$. A novel finding was that wheel running during reloading improved the oxidative phenotype of the gastrocnemius muscle, providing supporting evidence to the enhanced resistance to fatigue. The percentage of type IIa fibers was significantly increased while the percent of type $\mathrm{IIb} / \mathrm{x}$ fibers decreased with wheel running, favoring a fiber type shift of the muscle profile from glycolytic to more oxidative fibers. The gastrocnemius muscle contained too few type I fibers for this study to reach statistical significance, although the data suggested that voluntary wheel running increased the percentage of type I fibers, consistent with the oxidative shift seen in type 
IIa fibers. Furthermore, type IIa and IIb/x fibers had significantly larger CSA's, providing additional evidence of the efficacy of voluntary wheel running as a treatment.

\section{Voluntary wheel running activated satellite cells}

We hypothesized that voluntary wheel running would provide a sufficient stimulus to activate satellite cells during recovery without inducing injury. Satellite cells are known to be active in recovery from injury, but have not been established to have a role in normal reambulation reloading following HSU [23]. However, the question remained whether manipulating satellite cells to become activated during reloading would have an effect on muscle remodeling. A significant finding of this study is that voluntary wheel running during reloading does provide a sufficient stimulus to activate satellite cells, and that satellite cells do have a role in the improved muscle remodeling.

Figure 6 shows that new (BrdU-positive) nuclei are incorporated into reloaded myofibers as a result of voluntary wheel running. Pax7 is expressed in quiescent and proliferating satellite cells, but is down regulated as satellite cells differentiate and begin to express MyoD (Fig. 7). At 14 days of recovery, the incorporation of BrdU into myofibers, decreased expression of Pax 7 , and the increased expression of MyoD is interpreted as satellite cells having been activated, differentiated, and fused into existing myofibers. In the non-wheel running reloaded group, there was a modest increase in the number of BrdU positive nuclei, coupled with some of the mice within the group expressing high levels of Pax7, while others began to show minor increases in MyoD expression. We believe that this is due to a delayed response in satellite cell activation. Hypertrophy during the first two weeks of recovery occurs even when satellite cells are ablated [23], but a secondary adaptation in muscle recovery has been reported in soleus muscles beginning 
after 14 days of reloading [1]. The potential of satellite cells as mediating the secondary adaptation during HSU reloading warrants further investigation.

We speculate that satellite cell fusion has an active role in the morphological changes that occur during reloading with voluntary wheel running. A significant decrease in satellite cell activity is evidenced during the early phases of HSU [33]. This decrease precedes the oxidativeto-glycolytic fiber type shift, suggesting a relationship between myonuclear content and fiber type profile [33-35]. While it has been shown that type IIa fiber frequency can increase following 8 weeks of voluntary wheel running in satellite cell depleted mice, depletion of satellite cells also resulted in less distance run, slower velocities, impaired gait, and decreased grip strength [36]. We believe that the early role of satellite cell proliferation and fusion in muscle remodeling following atrophy warrants further investigation. HSU+WR mice had significantly more BrdU-positive nuclei than ControlWR mice. Additionally, the HSU+WR group had greater magnitudes of CSA increase during the 2 weeks of voluntary wheel running compared to the ControlWR mice (Fig. 5G). The HSU+WR group increase in CSA of type I and type IIb/x fibers from post-HSU values was 2-fold greater than the percent increase ControlWR mice had from Control values. The ControlWR group had no CSA increase in type IIa fibers, but the HSU+WR group increased type IIa fiber CSA by $96 \%$, as compared to the initial value of when voluntary wheel running was introduced (Control group and HSU group, respectively). These differences suggest that the morphological changes caused by voluntary wheel running are enhanced following atrophy, and this occurs with a significant increase in satellite cell incorporation. However, the present study design lacks the ability to differentiate whether the roles of exercise, satellite cells, or a combined effect of both are responsible for mediating specific adaptations to remodeling the muscle following atrophy. 


\section{Voluntary wheel running provides protective adaptation}

Although not reaching statistical significance, suspended mice ran $26 \%$ further $(P=0.054)$ than the non-suspended mice during the second week of wheel running. This is likely an indication that the reloaded muscle is actually compensating during reloading, as a result of wheel running stimulating a response that occurs solely in mice that were suspended. This is further evidenced in the evaluation of fatigue rate. Mice that were suspended were trending toward greater fatigue resistance than non-suspended mice that had access to wheel running (Fig. 4B). The increased fatigue resistance is consistent with the increased oxidative fiber type composition of the gastrocnemius muscle (Fig. 5). This compensation of increased oxidative features in the gastrocnemius muscle is in line with the secondary adaptation of an increase in type I fibers that is present in the soleus muscle, potentially as protective mechanism, after the first 2 weeks of reloading in mice [1].

The results indicate that the improvements in fatigue resistance are directly related to the morphological and potentially biochemical. Although we did not measure mitochondrial enzyme activity or abundance as this was outside the scope of this study, we hypothesize that the exercised muscles have improved mitochondrial function. PGC-1 $\alpha$ overexpression upregulates mitochondrial pro-fusion enzymes, providing a protective effect against disuse-atrophy [16]. The role of PGC-1 $\alpha$ during recovery has yet to be studied, and could potentially be a critical mediator of the mechanisms responsible for the improved muscle remodeling caused by voluntary wheel running.

Limitations. While we utilized the wheel running as a tool that would avoid causing unnecessary injury while retaining the benefits of exercise, we cannot fully rule out the possibility that the wheel running did cause some damage to muscle fibers or their membranes. 
A small limitation of this study is the inability to definitively prove that BrdU labeled nuclei are solely from satellite cells, but the preponderance of evidence suggests that the BrdU labeled nuclei are from satellite cells origins. The use of satellite-cell depleted transgenic mice could provide more definitive insight into the specific role of satellite cells in exercise mediated atrophy recovery.

\section{Conclusion}

This study revealed the novel finding that voluntary wheel running effectively improves the recovery of muscle function and morphology following HSU. Additionally, the study establishes novel evidence that satellite cells have a role in initial reloading, but require an underlying "priming" stimulus such as that provided by exercise to be activated. The results provide a rationale for conducting further studies that manipulate satellite cell activation as a therapeutic treatment for muscle disuse atrophy. Future investigation will be necessary to determine the exact roles and mechanisms of wheel running and satellite cells in recovery of muscle function and mass after HSU or other models of muscle disuse.

\section{References}

1. Feng H-Z, Chen X, Malek M, Jin J-P. Slow recovery of fatigue resistance in mouse soleus muscle corresponding to decreased mitochondrial function and a compensatory increase in type I slow fibers. Am J Physiol - Cell Physiol. 2015; ajpcell.00173.2015. doi:10.1152/ajpcell.00173.2015

2. Egawa T, Goto A, Ohno Y, Yokoyama S, Ikuta A, Suzuki M, et al. Involvement of AMPK in regulating slow-twitch muscle atrophy during hindlimb unloading in mice. Am J Physiol - Endocrinol Metab. 2015; ajpendo.00165.2015. doi:10.1152/ajpendo.00165.2015

3. Flück $\mathrm{M}$, Hoppeler $\mathrm{H}$. Molecular basis of skeletal muscle plasticity--from gene to form and function. Rev Physiol Biochem Pharmacol. 2003;146: 159-216. doi:10.1007/s10254-002-0004-7 
4. Bodine SC. Disuse-induced muscle wasting. Int J Biochem Cell Biol. 2013;45: 2200-2208. doi:10.1016/j.biocel.2013.06.011

5. LeBlanc A, Rowe R, Schneider V, Evans H, Hedrick T. Regional muscle loss after short duration spaceflight. Aviat Space Environ Med. 1995;66: 1151-1154.

6. Rittweger J, Frost HM, Schiess H, Ohshima H, Alkner B, Tesch P, et al. Muscle atrophy and bone loss after 90 days' bed rest and the effects of flywheel resistive exercise and pamidronate: results from the LTBR study. Bone. 2005;36: 1019-1029. doi:10.1016/j.bone.2004.11.014

7. Appell HJ. Skeletal muscle atrophy during immobilization. Int J Sports Med. 1986;7: 1-5. doi:10.1055/s-2008-1025725

8. Ohira Y, Jiang B, Roy RR, Oganov V, Ilyina-Kakueva E, Marini JF, et al. Rat soleus muscle fiber responses to 14 days of spaceflight and hindlimb suspension. J Appl Physiol Bethesda Md 1985. 1992;73: 51S-57S.

9. Stelzer JE, Widrick JJ. Effect of hindlimb suspension on the functional properties of slow and fast soleus fibers from three strains of mice. J Appl Physiol Bethesda Md 1985. 2003;95: 2425-2433. doi:10.1152/japplphysiol.01091.2002

10. Prisby RD, Nelson AG, Latsch E. Eccentric exercise prior to hindlimb unloading attenuated reloading muscle damage in rats. Aviat Space Environ Med. 2004;75: 941-946.

11. Kasper CE, White TP, Maxwell LC. Running during recovery from hindlimb suspension induces transient muscle injury. J Appl Physiol Bethesda Md 1985. 1990;68: 533-539.

12. Hanson AM, Stodieck LS, Cannon CMA, Simske SJ, Ferguson VL. Seven days of muscle re-loading and voluntary wheel running following hindlimb suspension in mice restores running performance, muscle morphology and metrics of fatigue but not muscle strength. J Muscle Res Cell Motil. 2010;31: 141-153. doi:10.1007/s10974-010-9218-5

13. Reid MB, Moylan JS. Beyond atrophy: redox mechanisms of muscle dysfunction in chronic inflammatory disease. J Physiol. 2011;589: 2171-2179. doi:10.1113/jphysiol.2010.203356

14. Widrick JJ, Maddalozzo GF, Hu H, Herron JC, Iwaniec UT, Turner RT. Detrimental effects of reloading recovery on force, shortening velocity, and power of soleus muscles from hindlimbunloaded rats. Am J Physiol Regul Integr Comp Physiol. 2008;295: R1585-1592.

doi:10.1152/ajpregu.00045.2008

15. Cannavino J, Brocca L, Sandri M, Bottinelli R, Pellegrino MA. PGC1- $\alpha$ over-expression prevents metabolic alterations and soleus muscle atrophy in hindlimb unloaded mice. J Physiol. 2014;592: 4575-4589. doi:10.1113/jphysiol.2014.275545

16. Cannavino J, Brocca L, Sandri M, Grassi B, Bottinelli R, Pellegrino MA. The role of alterations in mitochondrial dynamics and PGC-1 $\alpha$ over-expression in fast muscle atrophy following hindlimb unloading. J Physiol. 2015;593: 1981-1995. doi:10.1113/jphysiol.2014.286740 
17. Pellegrino MA, Desaphy J-F, Brocca L, Pierno S, Camerino DC, Bottinelli R. Redox homeostasis, oxidative stress and disuse muscle atrophy. J Physiol. 2011;589: 2147-2160.

doi:10.1113/jphysiol.2010.203232

18. Powers SK, Smuder A, Judge A. Oxidative stress and disuse muscle atrophy: cause or consequence? Curr Opin Clin Nutr Metab Care. 2012;15: 240-245. doi:10.1097/MCO.0b013e328352b4c2

19. Wang YX, Rudnicki MA. Satellite cells, the engines of muscle repair. Nat Rev Mol Cell Biol. 2012;13: 127-133. doi:10.1038/nrm3265

20. Mitchell PO, Pavlath GK. A muscle precursor cell-dependent pathway contributes to muscle growth after atrophy. Am J Physiol - Cell Physiol. 2001;281: C1706-C1715.

21. Alway SE, Pereira SL, Edens NK, Hao Y, Bennett BT. $\beta$-Hydroxy- $\beta$-methylbutyrate (HMB) enhances the proliferation of satellite cells in fast muscles of aged rats during recovery from disuse atrophy. Exp Gerontol. 2013;48: 973-984. doi:10.1016/j.exger.2013.06.005

22. Darr KC, Schultz E. Hindlimb suspension suppresses muscle growth and satellite cell proliferation. J Appl Physiol. 1989;67: 1827-1834.

23. Jackson JR, Mula J, Kirby TJ, Fry CS, Lee JD, Ubele MF, et al. Satellite cell depletion does not inhibit adult skeletal muscle regrowth following unloading-induced atrophy. Am J Physiol - Cell Physiol. 2012;303: C854-C861. doi:10.1152/ajpcell.00207.2012

24. Li P, Akimoto T, Zhang M, Williams RS, Yan Z. Resident stem cells are not required for exerciseinduced fiber-type switching and angiogenesis but are necessary for activity-dependent muscle growth. Am J Physiol - Cell Physiol. 2006;290: C1461-C1468. doi:10.1152/ajpcell.00532.2005

25. Kurosaka M, Naito H, Ogura Y, Kojima A, Goto K, Katamoto S. Effects of voluntary wheel running on satellite cells in the rat plantaris muscle. J Sports Sci Med. 2009;8: 51-57.

26. Irintchev A, Wernig A. Muscle damage and repair in voluntarily running mice: strain and muscle differences. Cell Tissue Res. 1987;249: 509-521.

27. Hao Y, Jackson JR, Wang Y, Edens N, Pereira SL, Alway SE. $\beta$-Hydroxy- $\beta$-methylbutyrate reduces myonuclear apoptosis during recovery from hind limb suspension-induced muscle fiber atrophy in aged rats. Am J Physiol Regul Integr Comp Physiol. 2011;301: R701-715.

doi:10.1152/ajpregu.00840.2010

28. Pistilli EE, Siu PM, Alway SE. Interleukin-15 responses to aging and unloading-induced skeletal muscle atrophy. Am J Physiol - Cell Physiol. 2007;292: C1298-C1304. doi:10.1152/ajpcell.00496.2006

29. Mohamed JS, Wilson JC, Myers MJ, Sisson KJ, Alway SE. Dysregulation of SIRT-1 in aging mice increases skeletal muscle fatigue by a PARP-1-dependent mechanism. Aging. 2014;6: 820-834.

30. Guderley H, Joanisse DR, Mokas S, Bilodeau GM, Garland Jr. T. Altered fibre types in gastrocnemius muscle of high wheel-running selected mice with mini-muscle phenotypes. Comp Biochem Physiol B Biochem Mol Biol. 2008;149: 490-500. doi:10.1016/j.cbpb.2007.11.012 
31. Yin H, Price F, Rudnicki MA. Satellite Cells and the Muscle Stem Cell Niche. Physiol Rev. 2013;93: 23-67. doi:10.1152/physrev.00043.2011

32. Olguin HC, Olwin BB. Pax-7 up-regulation inhibits myogenesis and cell cycle progression in satellite cells: a potential mechanism for self-renewal. Dev Biol. 2004;275: 375-388. doi:10.1016/j.ydbio.2004.08.015

33. Schultz E, Darr KC, Macius A. Acute effects of hindlimb unweighting on satellite cells of growing skeletal muscle. J Appl Physiol. 1994;76: 266-270.

34. Putman CT, Düsterhöft S, Pette D. Satellite cell proliferation in low frequency-stimulated fast muscle of hypothyroid rat. Am J Physiol - Cell Physiol. 2000;279: C682-C690.

35. Goldberg AL. Protein synthesis in tonic and phasic skeletal muscles. Nature. 1967;216: 1219-1220.

36. Jackson JR, Kirby TJ, Fry CS, Cooper RL, McCarthy JJ, Peterson CA, et al. Reduced voluntary running performance is associated with impaired coordination as a result of muscle satellite cell depletion in adult mice. Skelet Muscle. 2015;5: 41. doi:10.1186/s13395-015-0065-3 


\section{Chapter 5 - Findings \& Future Research}

The experiment was designed with 5 groups: Control, ControlWR, HSU, HSU+NoWR, and HSU+WR. By doing so we established that atrophy occurred in the gastrocnemius muscle (HSU vs. Control). Furthermore, we compared the effects of reloading with or without voluntary wheel running (HSU+NoWR vs. HSU+WR). Additionally, a control for voluntary wheel running was used to compare the relative magnitude of wheel running effects in non-suspended vs HSU mice (ControlWR vs. HSU+WR).

Specific Aim 1

Specific Aim 1 was to determine the effect of voluntary wheel running on muscle function following HSU. This aim was evaluated using in vivo maximal tetanic force and fatigue rate measurements. Mice were evaluated at the beginning of the study, following HSU, D7 recovery, and D14 recovery.

We found that the HSU model elicited a loss of mass and a decrease in force output, and a pseudo improvement in fatigue rate, consistent with published works [2,20,34]. Furthermore, our in vivo rate of fatigue measurement showed that HSU improved fatigue resistance, which is consistent with published data [2] but has been proposed to be a pseudo effect due to the muscle continuing to produce high levels of energy substrate even though the there is a reduction in contractile proteins [2]. A finding of particular interest in our study was that rather than first returning to baseline levels, HSU+WR mice retained fatigue resistance for the first 7 days after reloading and then enhanced fatigue resistance during the second 7 days of reloading. The improved fatigue resistance correlated with increased fiber CSA and a glycolytic-oxidative shift in fiber type frequency. It was recently discovered that during normal reambulation after HSU, in 
situ fatigue resistance of the soleus actually worsened following HSU for at least 15 days, before eventually fully recovering fatigability by 60 days of recovery [20]. Our results indicate that voluntary wheel running provides a prompt and effective therapy for improving functional recovery.

Maximal force output, muscle mass, and body mass were all fully recovered by D14 in both HSU+NoWR and HSU+WR mice.

Specific Aim 2

Specific Aim 2 was designed to determine the effect of voluntary wheel running on satellite cell proliferation and muscle morphology following HSU. This aim was evaluated using immunohistochemical staining and Western blot analysis at the conclusion of the study.

Satellite cells were activated in response to voluntary wheel running following HSU. A significant increase in BrdU-positive nuclei were found within the dystrophin border of gastrocnemius muscle fibers in the HSU+WR group. At 14 days of recovery, the incorporation of BrdU into myofibers, along with the decreased expression of Pax7, and the increased expression of MyoD is interpreted as satellite cells having been activated, differentiated, and fused into existing myofibers.

HSU+NoWR mice had significant increase in BrdU-positive nuclei during reloading, although this increase was significantly less than the HSU+WR group. A previous study published that the first 14 days of reloading recovery was not dependent on satellite cell activity [34]. Our findings are not necessarily inconsistent with that idea because we could not establish that the BrdU positive satellite cells had an active role in remodeling up to D14. The continued expression of Pax7 and only modest increases in MyoD expression suggest that satellite cells were 
proliferating at the point of muscle extraction, but have not yet differentiated and become myonuclei. The potential of a delayed onset in satellite cell activation during reloading following HSU is intriguing as the timing corresponds with the secondary adaptation phenomenon in HSU recovery described as beginning after the first 15 days of recovery [20] and warrants further investigation.

Voluntary wheel running also had an effect on tissue morphology. In contrast to HSU+NoWR mice, the HSU+WR mice had significantly greater frequencies of type IIa fibers, an oxidative glycolytic fiber type, and significantly decreased frequencies of type IIb/x fibers, a glycolytic fiber type. Although the type I frequency distribution in HSU+WR type I fibers did not reach significance, they were 5.5 times greater than the HSU+NoWR group. These changes in fiber frequency are evidence of enhanced glycolytic-to-oxidative fiber-type switching in the HSU+WR group. There were no significant differences between fiber type distribution in the gastrocnemius muscle of the HSU group and the HSU+NoWR group, implying that voluntary wheel running is responsible for the changes in fiber-type switching.

Although debated, some studies have suggested that myonuclear accretion is required for fiber-type switching [57,66]. A future study could clarify the role of satellite cell involvement in fiber type switching by using a satellite cell ablation model combined with voluntary wheel running following HSU.

In addition to changes in fiber type, HSU+WR mice significantly increased the CSA of all fiber types as compared to the control. HSU+NoWR mice also had significant increases in the CSA of all fiber types, but the increases were significantly less than those of HSU+WR mice. 


\title{
Chapter 6-Limitations
}

\author{
Study Design
}

A limitation in this study design is that the results are not directly translational to humans. Mice are small rodents and the effect of body weight loading on atrophied muscles has not been determined to be of a similar scale. Moreover, voluntary wheel running is viewed as a model to introduce low impact exercise, rather than as therapeutic recommendation for optimal exercise quantity.

Specific Aim 1

While the study monitored changes in force and fatigue at day 7 and 14 of recovery, these time-points are snapshots of the full recovery process. Due to variability in the distance individual mice ran or were affected by HSU, these points in recovery may not represent precisely equivalent progression of recovery within individual mice of the group.

\section{Specific Aim 2}

The study design did not permit us to determine the component of voluntary wheel running (e.g., distance run, running speed, intervals, potential for injury or adaptation, etc.) that might have been most important for activating satellite cells. Furthermore, voluntary wheel running could activate satellite cells by muscle injury and/or muscle adaptation to increased activity [57]. In this study, we were unable differentiate whether the muscle adaptation to voluntary wheel running or transient injury during reloading provided the requisite stimulus for satellite cell activation.

A small limitation of this study was that we were unable to definitively prove that BrdU labeled nuclei are solely from satellite cells, but the preponderance of evidence suggests that the 
BrdU labeled nuclei are from satellite cells origins. The use of satellite-cell depleted transgenic mice could provide more definitive insight into the specific role of satellite cells in exercise mediated atrophy recovery.

We also recognize that the selective histological evaluation of mixed fiber sections of the gastrocnemius muscle for CSA and fiber type frequency is not representative of the regions consisting homogenously of type IIb/x fibers. The justification for choosing this method was to analyze fiber areas that were undergoing change, and avoid masking phenotypic changes with regions that did not adapt to the reloading. The regions of homogenous type IIb/x fibers did not experience fiber type switching. See Appendix Figure 2 for further information. 


\section{References}

1. Zammit PS, Partridge TA, Yablonka-Reuveni Z. The skeletal muscle satellite cell: the stem cell that came in from the cold. J Histochem Cytochem Off J Histochem Soc. 2006;54: 1177-1191. doi:10.1369/jhc.6R6995.2006

2. Hanson AM, Stodieck LS, Cannon CMA, Simske SJ, Ferguson VL. Seven days of muscle re-loading and voluntary wheel running following hindlimb suspension in mice restores running performance, muscle morphology and metrics of fatigue but not muscle strength. J Muscle Res Cell Motil. 2010;31: 141-153. doi:10.1007/s10974-010-9218-5

3. Caiozzo VJ, Baker MJ, Herrick RE, Tao M, Baldwin KM. Effect of spaceflight on skeletal muscle: mechanical properties and myosin isoform content of a slow muscle. J Appl Physiol Bethesda Md 1985. 1994;76: 1764-1773.

4. Rapcsák M, Oganov VS, Szöör A, Skuratova SA, Szilágyi T, Takács O. Effect of weightlessness on the function of rat skeletal muscles on the biosatellite "Cosmos-1129." Acta Physiol Hung. 1983;62: 225-228.

5. Riley DA, Ellis S, Slocum GR, Satyanarayana T, Bain JL, Sedlak FR. Hypogravity-induced atrophy of rat soleus and extensor digitorum longus muscles. Muscle Nerve. 1987;10: 560-568.

doi:10.1002/mus.880100612

6. Widrick JJ, Knuth ST, Norenberg KM, Romatowski JG, Bain JL, Riley DA, et al. Effect of a 17 day spaceflight on contractile properties of human soleus muscle fibres. J Physiol. 1999;516 ( Pt 3): 915-930.

7. Ilyina-Kakueva El, Portugalov VV, Krivenkova NP. Space flight effects on the skeletal muscles of rats. Aviat Space Environ Med. 1976;47: 700-703.

8. Morey ER. Spaceflight and Bone Turnover: Correlation with a New Rat Model of Weightlessness. BioScience. 1979;29: 168-172. doi:10.2307/1307797

9. Ohira Y, Jiang B, Roy RR, Oganov V, Ilyina-Kakueva E, Marini JF, et al. Rat soleus muscle fiber responses to 14 days of spaceflight and hindlimb suspension. J Appl Physiol Bethesda Md 1985. 1992;73: 51S-57S.

10. Jiang B, Ohira Y, Roy RR, Nguyen Q, Ilyina-Kakueva El, Oganov V, et al. Adaptation of fibers in fasttwitch muscles of rats to spaceflight and hindlimb suspension. J Appl Physiol Bethesda Md 1985. 1992;73: 58S-65S.

11. Jiang B, Roy RR, Polyakov IV, Krasnov IB, Edgerton VR. Ventral horn cell responses to spaceflight and hindlimb suspension. J Appl Physiol Bethesda Md 1985. 1992;73: 107S-111S.

12. Musacchia XJ, Steffen JM, Fell RD, Dombrowski MJ, Oganov VW, Ilyina-Kakueva El. Skeletal muscle atrophy in response to 14 days of weightlessness: vastus medialis. J Appl Physiol Bethesda Md 1985. 1992;73: 44S-50S. 
13. Stauber WT, Fritz VK, Burkovskaya TE, Ilyina-Kakueva El. Effect of spaceflight on the extracellular matrix of skeletal muscle after a crush injury. J Appl Physiol Bethesda Md 1985. 1992;73: 74S-81S.

14. Fitts RH, Riley DR, Widrick JJ. Physiology of a microgravity environment invited review: microgravity and skeletal muscle. J Appl Physiol Bethesda Md 1985. 2000;89: 823-839.

15. Caiozzo VJ, Haddad F, Baker MJ, Herrick RE, Prietto N, Baldwin KM. Microgravity-induced transformations of myosin isoforms and contractile properties of skeletal muscle. J Appl Physiol Bethesda Md 1985. 1996;81: 123-132.

16. McDonald KS, Delp MD, Fitts RH. Fatigability and blood flow in the rat gastrocnemius-plantarissoleus after hindlimb suspension. J Appl Physiol Bethesda Md 1985. 1992;73: 1135-1140.

17. Stelzer JE, Widrick JJ. Effect of hindlimb suspension on the functional properties of slow and fast soleus fibers from three strains of mice. J Appl Physiol Bethesda Md 1985. 2003;95: 2425-2433. doi:10.1152/japplphysiol.01091.2002

18. Steffen JM, Robb R, Dombrowski MJ, Musacchia XJ, Mandel AD, Sonnenfeld G. A suspension model for hypokinetic/hypodynamic and antiorthostatic responses in the mouse. Aviat Space Environ Med. 1984;55: 612-616.

19. Caiozzo VJ, Baker MJ, Baldwin KM. Novel transitions in MHC isoforms: separate and combined effects of thyroid hormone and mechanical unloading. J Appl Physiol Bethesda Md 1985. 1998;85: 2237-2248.

20. Feng $\mathrm{H}-\mathrm{Z}$, Chen $\mathrm{X}$, Malek $\mathrm{M}$, Jin J-P. Slow recovery of fatigue resistance in mouse soleus muscle corresponding to decreased mitochondrial function and a compensatory increase in type I slow fibers. Am J Physiol - Cell Physiol. 2015; ajpcell.00173.2015. doi:10.1152/ajpcell.00173.2015

21. Fujii N, Jessen N, Goodyear LJ. AMP-activated protein kinase and the regulation of glucose transport. Am J Physiol Endocrinol Metab. 2006;291: E867-877. doi:10.1152/ajpendo.00207.2006

22. Powers SK, Kavazis AN, DeRuisseau KC. Mechanisms of disuse muscle atrophy: role of oxidative stress. Am J Physiol Regul Integr Comp Physiol. 2005;288: R337-344. doi:10.1152/ajpregu.00469.2004

23. Fujino H, Ishihara A, Murakami S, Yasuhara T, Kondo H, Mohri S, et al. Protective effects of exercise preconditioning on hindlimb unloading-induced atrophy of rat soleus muscle. Acta Physiol Oxf Engl. 2009;197: 65-74. doi:10.1111/j.1748-1716.2009.01984.x

24. Pellegrino MA, Desaphy J-F, Brocca L, Pierno S, Camerino DC, Bottinelli R. Redox homeostasis, oxidative stress and disuse muscle atrophy. J Physiol. 2011;589: 2147-2160. doi:10.1113/jphysiol.2010.203232

25. Powers SK, Smuder A, Judge A. Oxidative stress and disuse muscle atrophy: cause or consequence? Curr Opin Clin Nutr Metab Care. 2012;15: 240-245. doi:10.1097/MCO.0b013e328352b4c2 
26. Cannavino J, Brocca L, Sandri M, Bottinelli R, Pellegrino MA. PGC1- $\alpha$ over-expression prevents metabolic alterations and soleus muscle atrophy in hindlimb unloaded mice. J Physiol. 2014;592: 4575-4589. doi:10.1113/jphysiol.2014.275545

27. Brocca L, Pellegrino MA, Desaphy J-F, Pierno S, Camerino DC, Bottinelli R. Is oxidative stress a cause or consequence of disuse muscle atrophy in mice? A proteomic approach in hindlimbunloaded mice. Exp Physiol. 2010;95: 331-350. doi:10.1113/expphysiol.2009.050245

28. Cannavino J, Brocca L, Sandri M, Grassi B, Bottinelli R, Pellegrino MA. The role of alterations in mitochondrial dynamics and PGC-1 $\alpha$ over-expression in fast muscle atrophy following hindlimb unloading. J Physiol. 2015;593: 1981-1995. doi:10.1113/jphysiol.2014.286740

29. Egawa T, Ohno Y, Goto A, Ikuta A, Suzuki M, Ohira T, et al. AICAR-induced activation of AMPK negatively regulates myotube hypertrophy through the HSP72-mediated pathway in C2C12 skeletal muscle cells. Am J Physiol Endocrinol Metab. 2014;306: E344-354.

doi:10.1152/ajpendo.00495.2013

30. Egawa T, Goto A, Ohno Y, Yokoyama S, Ikuta A, Suzuki M, et al. Involvement of AMPK in regulating slow-twitch muscle atrophy during hindlimb unloading in mice. Am J Physiol - Endocrinol Metab. 2015; ajpendo.00165.2015. doi:10.1152/ajpendo.00165.2015

31. Widrick JJ, Maddalozzo GF, Hu H, Herron JC, Iwaniec UT, Turner RT. Detrimental effects of reloading recovery on force, shortening velocity, and power of soleus muscles from hindlimbunloaded rats. Am J Physiol Regul Integr Comp Physiol. 2008;295: R1585-1592.

doi:10.1152/ajpregu.00045.2008

32. Narici M, Kayser B, Barattini P, Cerretelli P. Effects of 17-day spaceflight on electrically evoked torque and cross-sectional area of the human triceps surae. Eur J Appl Physiol. 2003;90: 275-282. doi:10.1007/s00421-003-0955-7

33. LeBlanc A, Lin C, Shackelford L, Sinitsyn V, Evans H, Belichenko O, et al. Muscle volume, MRI relaxation times (T2), and body composition after spaceflight. J Appl Physiol Bethesda Md 1985. 2000;89: 2158-2164.

34. Jackson JR, Mula J, Kirby TJ, Fry CS, Lee JD, Ubele MF, et al. Satellite cell depletion does not inhibit adult skeletal muscle regrowth following unloading-induced atrophy. Am J Physiol - Cell Physiol. 2012;303: C854-C861. doi:10.1152/ajpcell.00207.2012

35. Kasper CE. Sarcolemmal disruption in reloaded atrophic skeletal muscle. J Appl Physiol. 1995;79: 607-614.

36. Riley DA, Ellis S, Giometti CS, Hoh JF, Ilyina-Kakueva EI, Oganov VS, et al. Muscle sarcomere lesions and thrombosis after spaceflight and suspension unloading. J Appl Physiol Bethesda Md 1985. 1992;73: 33S-43S.

37. Riley DA, Ellis S, Slocum GR, Sedlak FR, Bain JL, Krippendorf BB, et al. In-flight and postflight changes in skeletal muscles of SLS-1 and SLS-2 spaceflown rats. J Appl Physiol Bethesda Md 1985. 1996;81: 133-144. 
38. Riley DA, Bain JLW, Romatowski JG, Fitts RH. Skeletal muscle fiber atrophy: altered thin filament density changes slow fiber force and shortening velocity. Am J Physiol Cell Physiol. 2005;288: C360365. doi:10.1152/ajpcell.00386.2004

39. Riley DA, Thompson JL, Krippendorf BB, Slocum GR. Review of spaceflight and hindlimb suspension unloading induced sarcomere damage and repair. Basic Appl Myol BAM. 1995;5: 139-145.

40. Lee K, Lee YS, Lee M, Yamashita M, Choi I. Mechanics and fatigability of the rat soleus muscle during early reloading. Yonsei Med J. 2004;45: 690-702. doi:10.3349/ymj.2004.45.4.690

41. Bengt Saltin PDG. Skeletal Muscle Adaptability: Significance for Metabolism and Performance. Skelet Muscle Handb Physiol. 2010;10. doi:10.1002/cphy.cp100119

42. Warren GL, Stallone JL, Allen MR, Bloomfield SA. Functional recovery of the plantarflexor muscle group after hindlimb unloading in the rat. Eur J Appl Physiol. 2004;93: 130-138.

doi:10.1007/s00421-004-1185-3

43. Kasper CE, White TP, Maxwell LC. Running during recovery from hindlimb suspension induces transient muscle injury. J Appl Physiol Bethesda Md 1985. 1990;68: 533-539.

44. Anzil AP, Sancesario G, Massa R, Bernardi G. Myofibrillar disruption in the rabbit soleus muscle after one-week hindlimb suspension. Muscle Nerve. 1991;14: 358-369.

doi:10.1002/mus.880140411

45. Fridén J, Lieber RL. Segmental muscle fiber lesions after repetitive eccentric contractions. Cell Tissue Res. 1998;293: 165-171.

46. Fridén J, Sjöström M, Ekblom B. Myofibrillar damage following intense eccentric exercise in man. Int J Sports Med. 1983;4: 170-176.

47. Prisby RD, Nelson AG, Latsch E. Eccentric exercise prior to hindlimb unloading attenuated reloading muscle damage in rats. Aviat Space Environ Med. 2004;75: 941-946.

48. Wang YX, Rudnicki MA. Satellite cells, the engines of muscle repair. Nat Rev Mol Cell Biol. 2012;13: 127-133. doi:10.1038/nrm3265

49. Alway SE, Bennett BT, Wilson JC, Sperringer J, Mohamed JS, Edens NK, et al. Green tea extract attenuates muscle loss and improves muscle function during disuse, but fails to improve muscle recovery following unloading in aged rats. J Appl Physiol Bethesda Md 1985. 2015;118: 319-330. doi:10.1152/japplphysiol.00674.2014

50. Alway SE, Bennett BT, Wilson JC, Edens NK, Pereira SL. Epigallocatechin-3-gallate improves plantaris muscle recovery after disuse in aged rats. Exp Gerontol. 2014;50: 82-94. doi:10.1016/j.exger.2013.11.011

51. Siu PM, Pistilli EE, Alway SE. Apoptotic responses to hindlimb suspension in gastrocnemius muscles from young adult and aged rats. Am J Physiol Regul Integr Comp Physiol. 2005;289: R1015-1026. doi:10.1152/ajpregu.00198.2005 
52. Allen DL, Roy RR, Edgerton VR. Myonuclear domains in muscle adaptation and disease. Muscle Nerve. 1999;22: 1350-1360.

53. Carlos Eduardo Teixeira JAD. Changes in cross sectional area per myonucleus on mice soleus muscle during one week of hindlimb suspension reinforce the concept of myonuclear domain. Arch Exerc Health Dis. 2011;2: 76-80. doi:10.5628/aehd.v2i1.92

54. Mitchell PO, Pavlath GK. A muscle precursor cell-dependent pathway contributes to muscle growth after atrophy. Am J Physiol - Cell Physiol. 2001;281: C1706-C1715.

55. Alway SE, Pereira SL, Edens NK, Hao Y, Bennett BT. $\beta$-Hydroxy- $\beta$-methylbutyrate (HMB) enhances the proliferation of satellite cells in fast muscles of aged rats during recovery from disuse atrophy. Exp Gerontol. 2013;48: 973-984. doi:10.1016/j.exger.2013.06.005

56. Kornasio R, Riederer I, Butler-Browne G, Mouly V, Uni Z, Halevy O. Beta-hydroxy-betamethylbutyrate $(\mathrm{HMB})$ stimulates myogenic cell proliferation, differentiation and survival via the MAPK/ERK and PI3K/Akt pathways. Biochim Biophys Acta. 2009;1793: 755-763. doi:10.1016/j.bbamcr.2008.12.017

57. Li P, Akimoto T, Zhang M, Williams RS, Yan Z. Resident stem cells are not required for exerciseinduced fiber-type switching and angiogenesis but are necessary for activity-dependent muscle growth. Am J Physiol - Cell Physiol. 2006;290: C1461-C1468. doi:10.1152/ajpcell.00532.2005

58. Kurosaka M, Naito H, Ogura Y, Kojima A, Goto K, Katamoto S. Effects of voluntary wheel running on satellite cells in the rat plantaris muscle. J Sports Sci Med. 2009;8: 51-57.

59. Irintchev A, Wernig A. Muscle damage and repair in voluntarily running mice: strain and muscle differences. Cell Tissue Res. 1987;249: 509-521.

60. Zhang S-J, Bruton JD, Katz A, Westerblad H. Limited oxygen diffusion accelerates fatigue development in mouse skeletal muscle. J Physiol. 2006;572: 551-559. doi:10.1113/jphysiol.2005.104521

61. Guderley H, Joanisse DR, Mokas S, Bilodeau GM, Garland Jr. T. Altered fibre types in gastrocnemius muscle of high wheel-running selected mice with mini-muscle phenotypes. Comp Biochem Physiol B Biochem Mol Biol. 2008;149: 490-500. doi:10.1016/j.cbpb.2007.11.012

62. Hao $\mathrm{Y}$, Jackson JR, Wang $\mathrm{Y}$, Edens N, Pereira SL, Alway SE. $\beta$-Hydroxy- $\beta$-methylbutyrate reduces myonuclear apoptosis during recovery from hind limb suspension-induced muscle fiber atrophy in aged rats. Am J Physiol Regul Integr Comp Physiol. 2011;301: R701-715. doi:10.1152/ajpregu.00840.2010

63. Pistilli EE, Siu PM, Alway SE. Interleukin-15 responses to aging and unloading-induced skeletal muscle atrophy. Am J Physiol - Cell Physiol. 2007;292: C1298-C1304. doi:10.1152/ajpcell.00496.2006

64. Mohamed JS, Wilson JC, Myers MJ, Sisson KJ, Alway SE. Dysregulation of SIRT-1 in aging mice increases skeletal muscle fatigue by a PARP-1-dependent mechanism. Aging. 2014;6: 820-834. 
65. Liu H, Eksarko P, Temkin V, Haines GK, Perlman H, Koch AE, et al. Mcl-1 Is Essential for the Survival of Synovial Fibroblasts in Rheumatoid Arthritis. J Immunol. 2005;175: 8337-8345. doi:10.4049/jimmunol.175.12.8337

66. Putman CT, Düsterhöft S, Pette D. Satellite cell proliferation in low frequency-stimulated fast muscle of hypothyroid rat. Am J Physiol - Cell Physiol. 2000;279: C682-C690. 


\section{Appendix: Additional Figures}
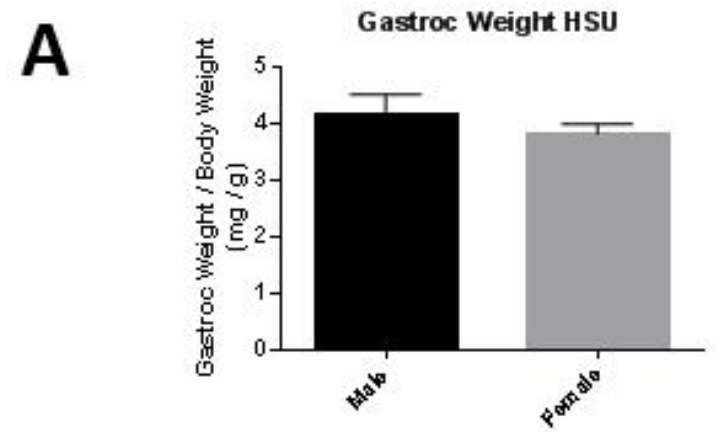

C

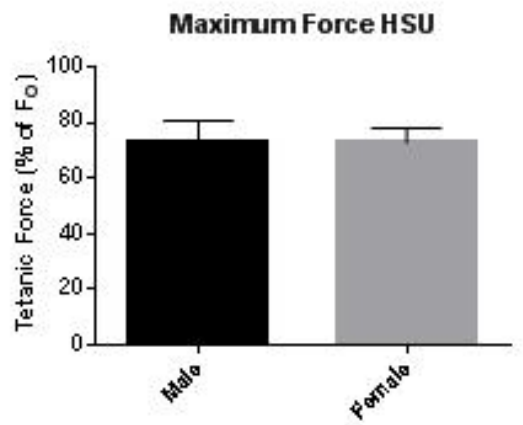

B

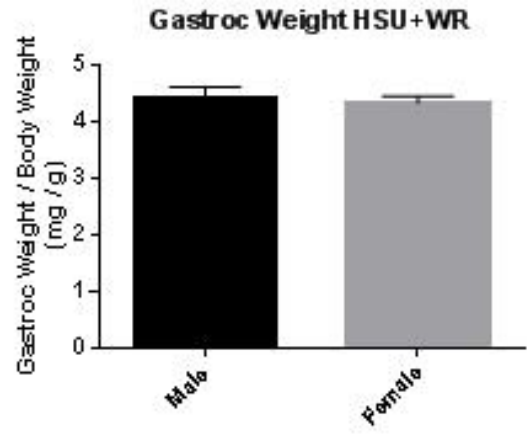

D

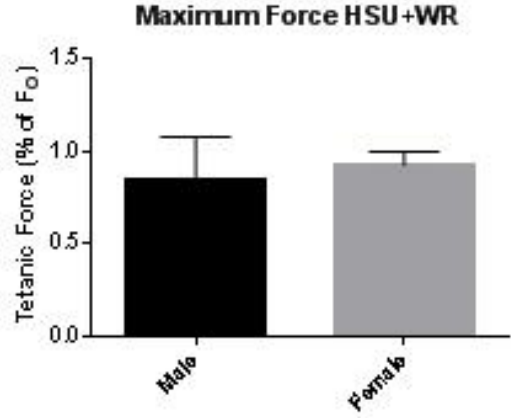

Appendix Figure 1: Male vs Female measurement. A-E: Graphs are comparison of male vs. female mice within each HSU and HSU+WR groups (n=3). A-B: Graphs depict gastrocnemius weight normalized to body weight. C-D: Graphs depict maximum force out put within HSU and HSU+WR groups. No statistical differences were measured between groups using t-tests $(P \leq 0.05)$.

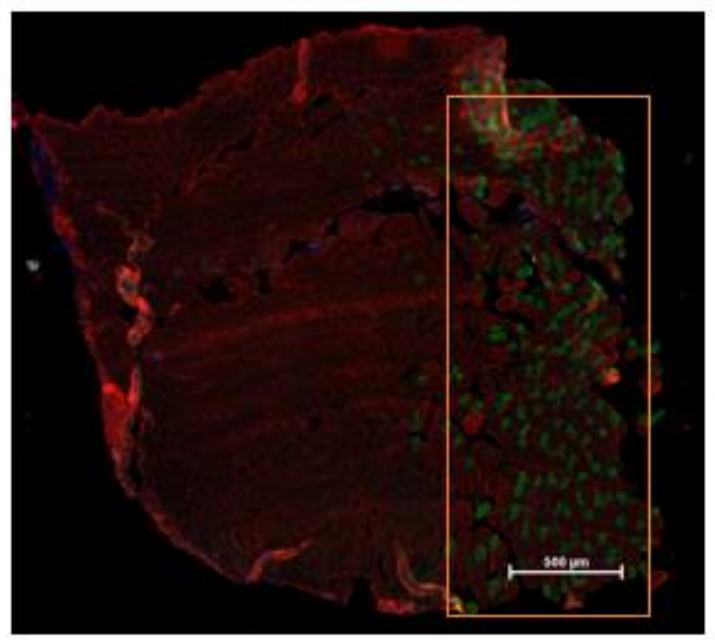

Appendix Figure 2: Histology Imaging. As seen in this representative image, imaging was focused on the area within the rectangle to enhance detection of fiber type switching. The authors were blinded to group fibers belonged prevent bias in image selection. 


\section{Inflammation}

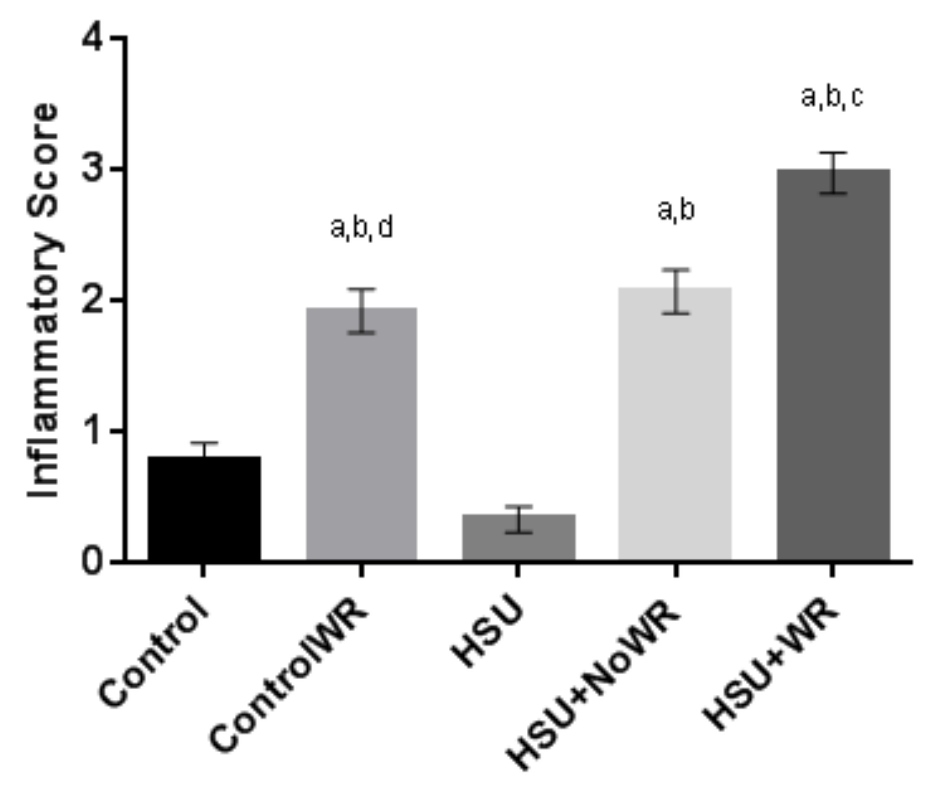

Appendix Figure 3: Inflammatory score. Inflammation response to reloading was scored according to published method [20,68]. Briefly, inflammation was scored in a blinded manner on a scale of 0-4: $0=$ no inflammation, 1 = few scattered inflammatory cells, 2 = clusters of inflammatory cells, 3 = diffuse infiltrate of inflammatory cells, 4 = dense sheets of inflammatory cells, including lymphoid follicles. All BrdU-positive cells that were within dystrophin border were considered as inflammation for determining the inflammatory score. Values are presented as mean \pm SE. ${ }^{a} p \leq 0.05$ vs. Control; $b P \leq 0.05$ vs. HSU; $c p \leq 0.05$ vs. HSU+NoWR; $d P \leq 0.05$ vs. HSU+WR. Statistical analysis was performed using one-way ANOVA with Tukey post-hoc test. 